\title{
NARRATIVA Y REALIDADES DE LA CAMORRA NAPOLITANA ENTRE ESTRUCTURAS ORGANIZATIVAS Y MODELOS REPRESIVOS
}

\author{
MICHELANGELO PASCALI ${ }^{*}$
}

\section{Resumen}

¿Qué representa la Camorra hoy? ¿Cuáles son sus características distintivas? ¿Cuál es la relación entre la violencia generalizada y la infiltración en los grandes asuntos públicos? ¿Qué función desempeñan los medios en delinear historias de la mafia y en orientar las actitudes criminales? ¿Cuáles son los problemas que surgen y deben abordarse para reprimir a los grupos de la Camorra?

\section{Palabras clave:}

Camorra, mafia, medios de comunicación, violencia, represión.

\begin{abstract}
What does Camorra represent today? What are Camorra distinctive traits? Is there any link between common use of violence and criminal infiltration in lucrative public affairs? What role do media play in influencing and shaping criminal behaviours? What are the issues that need to be assessed during the implementation of a repression strategy of Camorra related criminal groups?
\end{abstract}

\section{Keywords:}

Camorra, mafia, Mass Media, violence, repression.

\footnotetext{
1 *Investigador, Doctor en Derecho, Università degli Studi di Napoli “Parthenope", Dipartimento di Giurisprudenza, via Generale Parisi n. 13, 80132, Napoli (Italia), michelangelo.pascali@uniparthenope.it.
} 


\section{La "mafia napolitana."}

Cuando se piensa en el crimen organizado italiano, generalmente viene a la mente la palabra «mafia», lo que significa que esa forma particular de asociación criminal se basa en reglas rígidas y especialmente en un código moral particular, como se cuenta en libros y películas famosas (in primis, El Padrino de Puzo y Coppola). ${ }^{2}$ Es así que, la "mafia italiana" es por lo general identificada con la tierra de Sicilia y su cultura, sobre todo, en lo relacionado con los valores de la familia (lo cual ha contribuido en gran medida al éxito mediático de su narrativa en los Estados Unidos de Norteamérica, en un lugar y en un momento afectado por una grave crisis de la familia).

Sin embargo, las formas de criminalidad organizada italiana no se pueden reducir a la Mafia siciliana, además adquirida sólo parcialmente: la idea de la Mafia siciliana realmente se modela más o menos por la imagen de esa la parte llamada "Cosa Nostra"; parte sustancial, por supuesto, pero no exclusiva.

Al menos otras tres formas históricas de "mafia" pueden encontrarse en Italia, la "ndrangheta en Calabria, la Sacra Corona Unita en Pulía y, por último, la Camorra napolitana.

Esta última, en verdad, es la forma más antigua de crimen organizado en el territorio italiano ${ }^{3}$ (dando forma a algunos modelos tradicionales universalmente conocidos) $\mathrm{y}^{4}{ }^{4}$ en cierto modo, la que ahora despierta más alarma pública; ya que actualmente es la más peligrosa, por algunos

2 La fama de estos productos, que comenzó en los años ' 70 , parece haber dado forma a cierta imagen del crimen organizado a nivel mundial. Este "modelo estético-conceptual" aún permanece, aunque también sufre la competencia actual de otros modelos.

3 «Of a very different stamp from the International were, and are, the Camorra, of Naples, and the less known Maffia, of Sicily, which may be called an insular copy of the older institution on the mainland»: "The Camorra" En: The New York Times 23 de julio de 1882. Trad.: «De un sello muy diferente al internacional fueron, y son, la Camorra, de Nápoles, y la menos conocida Maffia, de Sicilia, que puede llamarse una copia insular de la institución más antigua en el continente».

4 «La Camorra no es conocida como la Mafia siciliana, pero gran parte de la tradición y el romance asociados con la vida de los gángsters, sin embargo, se originó en Nápoles. Aunque Don Corleone de "Il Padrino" fue retratado como un siciliano en el libro, se inspiró en un líder de la Camorra. El verdadero Lucky Luciano murió de un ataque al corazón en el aeropuerto de Nápoles. Las familias de John Gotti y Tony Soprano no eran sicilianas, sino que venían de una ciudad cerca de Nápoles». CAVALIERE, Flavia: "Gomorrah". En: European Journal of English Studies, 2010, N 14:2. Págs. 173 y ss. (nuestra traducción). 
aspectos que afectan tanto a la seguridad pública como al cuidado del medio ambiente y del territorio del sur de Italia. ${ }^{5}$

\section{II. "Camorrare".}

Por lo tanto, si la Camorra puede entenderse como una forma de "mafia italiana", debe decirse que tiene su propia historia y características únicas que requieren de reflexiones específicas.

Aunque "mafia" la podemos, en términos generales, significar a un método/modelo paradigmático, ${ }^{6}$ la Camorra tiene, de hecho, su especificidad precisa. ${ }^{7}$ Ya concentrándonos en el término per se, tenemos una guía útil. Con la palabra «camorra», cuya etimología exacta es desde hace mucho tiempo objeto de debate sin que se haya llegado a una conclusión definitiva, se entiende y se pretende, al menos por tres siglos, como un acto de intimidación y de violencia. El antiguo verbo «camorrare» refiere, de hecho, a la comisión de un acto de indebida prevaricación en presencia de un abuso; y los abusos son sin duda elementos bases del actuar, incluso actual, de la Camorra. Sin embargo, camorrare o incluso

5 Imágenes de la Camorra y su relación con la cultura, la sociedad y el territorio, están presentes en algunas películas - entre ellos: I guappi (SCUTIERI Pasquale, 1974); Processo alla città (ZAMPA Luigi, 1972); Il camorrista (TORNATORE Giuseppe 1986); Luna rossa (CAPUANO Antonio, 2001); Certi bambini (FRAZZI Andrea, FRAZZI Antonio, 2004); Gomorra (GARRONE Matteo, 2008); Fortapàsc (RISI Marco, 2009); Una vita tranquilla (CUPELLINI Claudio, 2010); Tatanka (GAGLIARDI Giuseppe, 2011); L'intervallo (DI COSTANZO Leonardo, 2012); Perez (DE ANGELIS Edoardo, 2014); Veleno (OLIVARES Diego, 2017); L'equilibrio (MARRA Vincenzo, 2017); - y en algunos documentales - por ejemplo: Dossier camorra (MARRAZZO Joe, 1974 y 1981); Biùtiful cauntri (CALABRIA Esmeralda, D'AMBROSIO Andrea, RUGGIERO Peppe, 2007); Camorra (PATIERNO Francesco, 2018). Las dos primeras películas son representaciones muy novedosas de la antigua realidad camorrística. Luna rossa puede ser considerada una lectura interesante de la tragedia griega (que casi muestra un aspecto "ancestral" de la cultura familiar de Camorra). Otros se refieren a situaciones más recientes. Entre los documentales, los de Marrazzo indican situaciones de un pasado cercano y Biùtiful cauntri habla más ampliamente de la devastación ambiental hecha.

6 PALAZZO, Francesco: "La mafia hoy: evolución criminológica y legislativa". En: Ferré Olivé, Juan Carlos, Anarte Borrallo, Enrique (eds.): Delincuencia organizada. Aspectos penales, procesales y criminológicos. Universidad de Huelva, Huelva, 1999. Pág. 162. CACIAGLI, Mario: Clientelismo, corrupción y criminalidad organizada. Evidencias empiricas y propuestas teóricas a partir de los casos italianos. Centro de Estudios Constitucionales, Madrid, 1996. Pág. 112.

$7 \quad$ ZÚNIIGA RODRÍGUEZ, Laura: Criminalidad organizada y sistema de derecho penal. Contribución a la determinación del injusto penal de organización criminal. Comares, Granada, 2009. Págs. 91 y ss. 
«hacer la camorra» parecieran en el pasado tener un sentido más general con respecto al uso de hoy en día, no indicando, necesariamente, actos típicos de los miembros de una organizacion criminal estructurada. Solo en un cierto punto histórico el término "camorrista" pasa, de ser un adjetivo, a ser un sustantivo. ${ }^{8}$

Sobre el tema de la génesis y el significado de la terminología, cabe señalar que incluso la misma palabra "mafia" no siempre se ha referido a quienes pertenecen a los clanes criminales, sino que a individuos particularmente (y a su manera) valientes (no necesariamente acostumbrados a prácticas delictuales), cuyas acciones se basaban en un algo de coraje y en un honor especial. Se debe a "I mafiusi de la Vicaria", escrito en 1863 en idioma siciliano por Rizzotto, la difusión - y, de hecho, casi la creación - del uso del término "mafiosi" para los componentes de organizaciones criminales de este tipo. Antes de eso, de hecho, la calificación exacta era la de "camorristi", que también se encuentra en esta obra teatral. El éxito de este trabajo hizo que su título, que estaba utilizado solo para indicar un adjetivo de la mafia, terminara en realidad para indicar comúnmente a estos sujetos (así que las reglas de la figura de la antonomasia, consciente o inconscientemente, se han aplicado a los hechos reales). La popularidad de este drama - el cual finalmente fue forzosamente "arreglado" en clave moralizadora - además de haber contribuido a nombrar un fenómeno de una manera diferente a la real en aquel entonces, también dio lugar a una lectura distorsionada y deforme, simplificando manifestaciones complejas e incluso heterogéneas.

Hasta entonces, de hecho, el modelo de estas formas de criminalidad, como indicaban los términos en uso, fue el de la camorra (que todavía indica un "grado" de carrera de "poder" para "nrangheta calabresa9 y Mafia siciliana), difundido por todo el sur de Italia, a través de las grandes cárceles del Reino de las dos Sicilias. Esto es algo que necesita atención, porque todavía está en las características fundamentales de la Camorra napolitana, que en las cárceles y sobre las cárceles, se ha fundado su fuerte poder en ciertos períodos históricos. ${ }^{10}$

8 BENIGNO Francesco: "La questione delle origini: mafia, camorra e storia d'Italia”. En: Meridiana. Rivista di Studi Storici e Sociali, No 87, 2016. Págs. 125 y ss.

9 Tenga en cuenta que incluso el nombre de "ndrangheta vendría del griego antiguo «andragathia», que significa "fortaleza de ánimo".

10 Amplius: MARMO, Marcella: Il coltello e il mercato. La camorra prima e dopo l'Unità d'Italia. L'ancora del Mediterraneo, Nápoles-Roma, 2011. 


\section{Carácter y límites del fenómeno.}

Precisamente, esas breves y peculiares notas de introducción de la palabra "mafia", en el lenguaje común, con el significado que todavía tiene, nos permite introducir nuestras primeras reflexiones. En primer lugar, y esto lo confirma - si fuera necesario -, hablando de criminalidad organizada, la fuerza mediática del fenómeno parece estar fuera de discusión. La fascinación, la sorpresa y el miedo, que podemos encontrar en la opinión pública de siglo XIX, e incluso en el trabajo de los mismos eruditos del mismo siglo, cargados de positivismo, que la examinaban de un punto de vista antropológico, no parece en absoluto faltar a la palabra, sino que parece haber cambiado de forma. Justo este sentimiento fisiológico puede llevar a consideraciones erróneas e incorrectas. En la imaginación colectiva, la representación de organizaciones criminales, sean éstas y sus efectos cerca o lejos, inmediatamente o apenas perceptibles, de hecho, sigue sufriendo interpretaciones emocionales de diferentes formas ${ }^{11}$

Las lecturas parciales o equivocadas tampoco se limitan a una vulgata común, pero a veces tienen que ver también con estudiosos y, con mayor frecuencia, con profesionales de la política y de la ley.

Si el modelo de Cosa nostra parece ser predominante cuando se piensa en grupos criminales italianos organizados, también la consideración específica de la Camorra está a veces llena de análisis parciales.

Previamente, se debe tener en cuenta que esta pregunta toca además el problema más amplio (y, por supuesto, no solo el italiano) de la identificación exacta de los elementos específicos que rigen el delito de asociación delictiva. ${ }^{12}$ La complejidad del discurso, por tanto, resulta de la misma dificultad criminológica para entender el crimen organizado ${ }^{13}$ (como lo demuestra también la desproporción entre la gran extensión del fenómeno y la relativa escasez de estudios en esta área), ${ }^{14}$ aunque una

11 Lo que llevó a consolidar ideas que son el resultado tanto para de un pánico general como para de distorsiones románticas totales. Sobre el tema, ver SINDONI, Angelo: "Mafia, Camorra, 'Ndrangheta: el immaginario colectivo y la evolución". En: Cámara de Landa, Enrique, Morabito, Stefano (eds.): Mafia, 'Ndrangheta, Camorra. En los entresijos del poder paralelo. Universidad de Valladolid, Valladolid, 2005. Págs. 24 y ss.

12 LÓPEZ MUÑOZ, Julián: Criminalidad organizada. Aspectos jurídicos y criminológicos. Dykinson, Madrid, 2015. Págs. 62 y ss.

13 ZUÑIGA RODRIGUEZ, Laura: Criminalidad organizada y sistema de derecho penal, ob. cit. Págs. 30 y ss.

14 Aunque con una intensidad mucho menor, este dato también afectaría a Italia: PONTI, Gianluigi: "Criminalità organizzata e criminologia". En: Bandini, Tullio, Lagazzi, 
definición conceptual clara parece esencial ${ }^{15}$ (especialmente para reprimir asociaciones criminales de carácter mafioso). Sobre el tema, se oscila entre modelos legales, socioculturales, estructurales y económicos, construidos con diferentes propósitos. ${ }^{16}$ En la búsqueda de un esquema comúnmente admisible, también debemos mencionar la elaboración, dentro de la Unión Europea (específicamente por Europol), de once criterios (de los cuales al menos seis deben estar absolutamente presentes) para determinar la existencia de la criminalidad organizada. ${ }^{17}$ Ante la innegable heterogeneidad del crimen organizado, ${ }^{18}$ es posible, por consiguiente, detectar aspectos generalmente presentes en los grupos pero no siempre, y no necesariamente, típicos o esenciales. ${ }^{19}$ Claramente, la generalidad de estos trabajos de definición hace posible incluir en los esquemas propuestos fenómenos que no son trazables al "fenotipo" de la matriz mafiosa-camorrista. En cualquier caso, también se hizo hincapié en la existencia de una fuerte correlación entre los modelos propuestos para definir esencia y presencia de las mafias y las opciones de política criminal. ${ }^{20}$

Volviendo a la Camorra, analizando cuáles son sus características, se deben establecer algunos puntos fijos; por cierto, la Camorra es (exactamente) una manifestación de crimen organizado, que se define - en

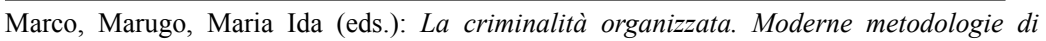
ricerca e nuove ipotesi esplicative. Giuffrè, Milano, 1993. Pág. 179.

15 Esto, especialmente en términos de contraste. En este aspecto, MEDINA ARIZA, Juan José: "Una introducción al estudio criminológico del crimen organizado". En: Ferré Olivé, Juan Carlos, Anarte Borrallo, Enrique (eds.): ob. cit. Pág. 111.

16 LAGAZZI, Marco, MARUGO, Maria Ida: "La ricerca in tema di criminalità organizzata: approcci interpretativi e problematiche metodologiche". En: Bandini, Tullio, Lagazzi, Marco, Marugo, Maria Ida (eds.): ob. cit. Pág. 3.

17 ZUÑIGA RODRIGUEZ, Laura: "Criminalidad organizada, derecho penal y sociedad: apuntes para el análisis". En: Sanz Mulas, Nieves (ed.): El desafio de la criminalidad organizada. Comares, Granada, 2006. Págs. 49 y ss. Los criterios identificados son los siguientes: 1. Colaboración de dos o más personas. 2. Distribución de tareas entre ellas. 3. Permanencia. 4. Control interno. 5. Sospechosas de la comisión de un delito grave. 6. Actividad internacional. 7. Violencia. 8. Uso de estructuras comerciales o de negocios. 9. Blanqueo de dinero. 10. Presión sobre el poder público. 11. Ánimo de lucro.

18 ANARTE BORRALLO, Enrique: "Conjeturas sobre la criminalidad organizada". En: Ferré Olivé, Juan Carlos, Anarte Borrallo, Enrique (eds.): ob. cit. Págs. 23 y ss.

19 MEDINA ARIZA, Juan José: "Una introducción al estudio criminológico del crimen organizado". En: Ferré Olivé, Juan Carlos, Anarte Borrallo, Enrique (eds.): ob. cit. Pág. 111.

20 BARATTA, Alessandro: "Mafia: rapporti tra modelli criminologici e scelte di politica criminale". En: Moccia, Sergio (ed.): Criminalità organizzata e risposte ordinamentali. Tra efficienza e garanzia. Esi, Nápoles, 1999. Pág. 94. 
general - como una forma de delincuencia asociativa que requiere de una organización estable y de varias personas para cometer muchos crímenes, diseñados para obtener, directamente $\mathrm{o}$ indirectamente, beneficios financieros o materiales.

Sin embargo, esta definición debe ser aclarada, ya que el tema en cuestión es ciertamente una forma de delincuencia organizada (tautológicamente de forma camorrista-mafiosa), concebida como una "sociedad" orientada a la búsqueda de una ganancia ilegal; dirigida externamente a intimidar y dominar el territorio y basada interiormente en la fundación y el mantenimiento de una unión exclusiva entre sus asociados, cuyas reglas (en primer lugar la lealtad, el secreto y la obediencia al superior) están absolutamente compartidas, adquiriendo un significado particular en el marco en el cual se insertan. También, nótense cómo se interpreta el requisito de lealtad en el sentido de una prohibición a una "colaboración desinteresada" ("comparaggio") ${ }^{21}$ con los representantes de la ley. Se ve desde la definición citada la importancia de los elementos que podemos delinear como materiales e ideales. El plan cultural-relacional, por lo tanto, aparece en una posición central (anticipamos ahora que esto, por un lado, aclara los límites particulares del fenómeno, por el otro, crea problemas con la identificación y el contraste de las manifestaciones criminales que tienen aspectos divergentes en comparación con este punto). En este sentido, es fundamental la obligación de la "ley del silencio" ("omertà") hacia la organización, que tienen que respetar tanto los miembros, como los no miembros que tienen que ver con ella (por ejemplo, que se encuentren en una trayectoria o en alguno de los grados que intercepte sus negocios o que están en varios aspectos presentes en "su" territorio, también como víctimas). No es casualidad que utilizamos la adjetivación de 'posesión' del territorio, debido a que estas organizaciones aspiran a ejercer una especie de "soberanía territorial", no sólo actuando como un "embudo" de algunos grandes flujos de dinero (piénsese a la materia de licitaciones públicas), ${ }^{22}$ sino que también mediante imposición de un tipo de tributo, claramente entendido como forma de extorsión.

21 SALES, Isaia: Storia dell'Italia mafiosa. Rubettino, Soveria Mannelli (Cz), 2015. Págs. 200 y ss.

22 PASCALI, Michelangelo: Camorra, economia e società. Ontologia dei sistemi criminali e delle ingerenze illecite nell'area dei pubblici appalti. Giappichelli, Turín, 2012. Págs. 160 y ss. 
No obstante, más allá de lo que sugeriría el nombre «camorra», especialmente en cómo se lo utiliza, no estamos en presencia de un organismo solo, ya sea espacial o temporalmente. De hecho, nos encontramos frente a precisas cesuras históricas de esta manifestación criminal, así como a la presencia de grupos de camorra heterogéneos, muy diferentes e incluso contrastados entre sí. Este marco puede expresarse bien mediante el uso del término plural "camorre" ("camorras") para designar al fenómeno. ${ }^{23}$ El hecho de que no ha existido ${ }^{24}$ una sola camorra en términos de tiempo y también en términos de espacio, como lo hemos podido ver a lo largo de la historia, ya que han existido diferentes manifestaciones de esta, nacidas por razones subyacentes y similares, las cuales han sido afectadas por diferentes contingencias, determina que también el lado punitivo debe moverse en una perspectiva que toma en cuenta esta complejidad. Se puede notar, de hecho, que la represión se ha manifestada en diferentes formas y grados. La Camorra, debido a lo cual, en comparación con la pregunta sobre la definición ontológica del crimen organizado, responde a los criterios generalmente considerados y, de hecho, ayudó a fijarlos con su propia historia, pero con algunos elementos absolutamente originales, que solo pueden entenderse mediante análisis histórico-sociales.

\section{IV. "Como un espejo de problemas históricos".}

Pasando a mencionar muy brevemente su historia, vemos cómo la Camorra tiene antiguos orígenes, como evidencia de una representación cíclica (casi fisiológica) de problemas del territorio. Organizaciones de este tipo habrían existido en el Reino de Nápoles en la época del gobierno español (por lo menos desde el siglo XVI), en la apariencia de organizaciones criminales similares que, por tanto, se pueden considerar como amagos. ${ }^{25}$

Además, desde nuestros primeros testimonios seguros de una Camorra basada en elementos formales y relacionales similares a los actuales, aparece la no originalidad del fenómeno. Esto se refiere a los documentos

SALES, Isaia: La camorra le camorre. Editori riuniti, Roma, 1993.

24 (No ha habido y que no hay).

25 Nos referimos aquí a los numerosos grupos que las diversas Fuentes, han indicado como progenitores de la Camorra (por ejemplo, los "Compagnoni", mencionados en D’ADDOSIO, Carlo: Il duello dei camorristi. Editore Lello Pierro, Nápoles, 1893), antiguas bandas delincuentes con fuertes similitudes comparadas con algunas secciones de la Camorra moderna.
} 
establecidos para la fundación de la "Onorata Suggità" en el siglo XIX quien cuidadosamente fijaron los parámetros del código de acción y de moralidad de la Camorra, en términos de límites subjetivos y reglas de honor para el acceso a la organización, de necesaria complicidad y reticencia, y así sucesivamente - con cierta afinidad con los ritos y las reglas de las sociedades masónicas y secretas tan extendidas en esos siglos. ${ }^{26} \mathrm{~A}$ partir de este documento $-\mathrm{y}$ es el punto que nos interesa aquí - está claro que tal realidad tomó la calificación de "Sociedad Reformada", como evidencia de las fundaciones y refundaciones que también continuarán en tiempos posteriores.

Obviamente, cada una de estas "realizaciones criminales" tiene su propia especificidad, sobre todo en relación con los momentos históricos en que se interponen.

En el momento del pasaje de los Estados italianos pre-unitarios a la Unidad de Italia - que comportó el fin del más grande Reino Italiano de la época (de las dos Sicilias), que tenía a Nápoles como su capital - la Camorra adquiere una nueva función, siendo que el nuevo Estado italiano le asigna de hecho (a nivel colectivo) o incluso oficialmente (a nivel individual), una delegación a la gestión del orden público, basada en la idea y la efectividad de cierta legitimidad popular. Cabe recordar, a este respecto, las raíces populares de la figura de "guappo" - un término cuyo uso está registrado al menos desde 1841 y que deriva claramente de la palabra española "guapo», enfatizando así el valor de este tipo de sujeto - como responsable de la orden y como administrador de la justicia popular, del "callejón".

La ayuda de las mafias italianas, se requiere nuevamente durante la Segunda Guerra Mundial; esta vez por los aliados angloamericanos, particularmente en Sicilia. En Nápoles, sin embargo, no afectada por el desembarco de las tropas, la guerra tiene otro efecto; la ciudad está bastante destruida económicamente y urbanísticamente, siendo la ciudad más bombardeada de Italia. Blanco elegido al principio para sus industrias principales y su puerto militar central; más tarde, se debilita por la estrategia de bombardeo de Churchill y luego por el proceder de los Estados Unidos de Norteamérica para debilitar la relación entre el régimen fascista y la

26 Cabe señalar que la mezcla entre los presos políticos y los presos comunes presentes en las prisiones del siglo XIX en el sur de Italia ha permitido que las mafias tomen préstamos de organizaciones políticas rituales, estructuras y métodos de comunicación crípticos. 
población local. Y, aun después, sufre daños materiales y humanos a través de la practica de destrucción masiva realizada por los ex aliados alemanes.

El extenso daño no permite que los fondos del Plan Marshall recuperen plenamente a su aparato industrial (fondos que están destinados a las ciudades del norte de Italia, que han sufrido daños menores y por lo tanto más fácilmente remediables). En este momento, aparece un rol de reemplazo de los grupos de la Camorra, que utiliza las prácticas de contrabando perfeccionadas durante la guerra ${ }^{27} \mathrm{y}$ establece, a partir de algunas pequeñas áreas de la ciudad vieja, un más amplio y duradero comercio ilícito de cigarrillos, lo que permitirá salvar la ciudad del hambre, pero en parte entregándola a la lógica y a la fuerza de la Camorra. ${ }^{28}$

Otra importante etapa se da en el tiempo "cutoliano", donde Cutulo (un pequeño criminal de provincia de los años 80 , que tendrá un rol cada vez más importante) logra formular un peculiarísimo plan "políticocriminal", convirtiéndose así en una de las figuras de primer plano de la escena del crimen (por lo menos) italiano y haciendo incluso cambiar de piel a la Camorra. Posteriormente, aprovechando los grandes fondos para la reconstrucción de los territorios de la Campania, devastadas por el terremoto de $1980^{29}$ (fondos que se dispersaron en gran parte, a través de una cadena de ilegalidad y escándalos que vieron una fuerte interrelación entre el hampa y la política), ${ }^{30}$ se inventa un marco ideológico impregnado de ideas proletarias donde se introduce el concepto de "camorra-masa". Hemos mencionado que las cárceles han sido históricamente un lugar

27 «Ya todos saben que el mercado negro actúa bajo la protección de altos funcionarios de Allied Military Government. [...] En su cabeza está el coronel Charles Poletti, con el cual trabaja, con mansión de consejero, Vito Genovese, ex jefe de la mafia americana. Genovese nació en un pueblo cerca de Nápoles, quedando en estrecho contacto con la criminalidad local; esta claro además que muchos de los alcaldes mafiosos o camorristos, que tomaron posesión de los pueblos aquí en el alrededor, son hombres suyos. Estos hechos, que eran antes secretos de Estado están ahora conocidos hasta para el hombre de la calle. Sin embargo, no se hace nada. No obstante, muchos informes alarmantes sobre sus actividades, los altos funcionarios de el AMG permanecen donde están» (LEWIS, Norman: Naples '44. William Collins, Londres, 1978; nuestra traducción).

28 El reforzamiento de la Camorra parece ser evidente especialmente por la parte de la Camorra ciudadana, mientras que en la así dicha Zona de Camorra de los territorios de Provincia la Camorra ya poseía fuertes raíces, no obstante, el tentativo de represión del régimen de Mussolini.

29 Ver Terremoto sommerso (MARRAZZO Joe, 1980) y Terremoto anno quarto (MARRAZZO Joe, 1984).

$30 \quad$ Brevemente, "Le mani della politica su 58.000 miliardi di lire stanziati per la ricostruzione dopo il sisma dell'80". En: Il Tempo del 8 de abril de 2009. Por cierto, cabe 
importante para el poder de la Camorra; lo que podríamos definir como una primera "acumulación primitiva" de dinero y de poder, que se basa en la práctica habitual de extorsión en el interior de los institutos penitenciarios (se sabe que la primera Camorra presumía de "sacar la sangre de los piojos", entendiéndose esto como una capacidad de explotar incluso a los menos afortunados, quienes, como delincuentes, son los menos protegido por el poder legal) ${ }^{31}$ y Cutolo vuelve a proponer 'acertadamente', la centralidad de las prisiones en el esquema de poder de la Camorra. Él es un jefe sin territorio, como comúnmente se entiende; su verdadero territorio, de su pertenencia y sujeto a su control, es la prisión, donde ejerce su influencia para 'ayudar' en los problemas de la vida cotidiana de la cárcel y también dar un marco de identidad a una multitud de "dispersos" (es decir, sujetos socialmente "sin conexión real"; económicamente y culturalmente no integrados); constituyendo su propio ejército en el bajo mundo y reorganizando "ideológicamente" la Camorra, dándole el nombre de "Nuova Camorra Organizzata". Su éxito y su fin, deben ser relacionados, además, con la debilidad y la reacción de los otros grupos de la Camorra (la "Nuova famiglia", en primer lugar), con la incapacidad o la capacidad represiva del Estado; y con el interés o desinterés por parte del poder estatal de 'acordarse' con el proyecto cutoliano.

Hay que decir que el fracaso de este proyecto vuelve a proponer la Camorra napolitana como un conjunto de grupos diferentes, que se relacionan entre sí, en términos de conveniencia y, a menudo, de antagonismo.

\section{Organización 'desestructurada'.}

Todos los casos mencionados muestran, por lo tanto, situaciones y momentos de extrema fragilidad del tejido económico y políticoadministrativo del territorio. En ese aspecto, la persistencia de problemas económicos, administrativos y sociales se pueden atribuir a concausas desde donde deriva el problema de la Camorra, que a su vez se refleja en la estructura de la sociedad, lo que agrava aún más la situación.

señalar que incluso las reconstrucciones de hoy en otros territorios italianos después de los terremotos recientes ven el riesgo de infiltración de Camorra: "STOP a la mafia". En: https:// www.larazon.es/internacional/stop-a-la-mafia-PG13409006\#.Ttt1KrLLM2eudT8.

31 MONNIER, Marco: La camorra: mystères de Naples. Michel Lévy frères, París, 1863. Pág. 115. 
Las operaciones que querían resolver de alguna manera estos problemas han registrado múltiples fallas en diferentes niveles, incluido el puramente urbano-arquitectónico. En este punto, solo debe recordarse que, en las últimas décadas, el malestar social y la delincuencia generalizada se han extendido, pero no se han movido, desde la horizontalidad de los "vasci" 32 a la verticalidad de los nuevos suburbios. ${ }^{33}$

Por supuesto, la amplitud y el alcance de la Camorra indiscutiblemente la identifican como un fenómeno, con una extensión no solo criminal, sino también económica y social. ${ }^{34}$

En relación con la situación actual, se puede decir, en resumen, que la Camorra está compuesta en la actualidad por grupos fuertes, peligrosos y sanguinarios, pero completamente independientes unos de los otros, los cuales no son capaces de organizarse, en el sentido de coordinarse entre sí, dedicados a negocios rentables, pero también a conflictos interminables. ${ }^{35}$

Justamente por este motivo, la Camorra podría ser calificada como "crimen desorganizado"; 36 es decir que tiene, por lo tanto, una relación particular con la desorganización social, desde la cual proviene, reflejándola parcialmente, pero no "resolviéndola".

Sin embargo, podemos distinguir entre un nivel local y otro global de la Camorra (aunque no hay que olvidarse de su aspecto glocal, capaz de potenciar los recursos locales y las tradiciones en un contexto internacional); niveles que, desde afuera, parecen casi incompatibles.

Si el primero está hecho de violencia, fragmentación y escalada de poder, incluso generacionales, el segundo nivel se dirige hacia beneficios racionales y normas de una eficiente economía racional.

Estructuralmente, está claro, sin embargo, que la Camorra aparece como un sistema muy individualista, no separándose de la histórica "anarquía

32 "Basso (Napoli)". En: https://it.wikipedia.org/wiki/Basso_(Napoli).

33 PASCALI, Michelangelo: Progetto Scampia. Sulla questione della periferia nord di Napoli. Giappichelli, Turín, 2017.

34 Así, el fiscal de Nápoles Giovanni Melillo; por ejemplo, en "Camorra, l'allarme del procuratore Melillo: «Non solo bande, professionisti e imprese aiutano i clan»". En: https://www.ilmattino.it/napoli/cronaca/camorra_allarme_procuratore_melillo-3286606. html.

35 LUPO, Salvatore: "Criminalità organizzata". En: http://www.treccani.it/ enciclopedia/criminalita-organizzata/.

36 SAVONA, Erneso Ugo: "Le organizzazione criminali in Europa viste dall'esperienza italiana". En: Fiandaca Giovanni, Visconti, Costantino (eds.): Scenari di mafia. Orizzonte criminologico e innovazioni normative. Giappichelli, Turín, 2010. Pág. 34. 
napolitana", desarrollada por el carácter y por la ausencia o la distancia de un poder oficial establecido (basta con pensar al período histórico del virreinato).

De manera más precisa, se pueden destacar tres niveles, cada uno de los cuales se mueve de acuerdo a una cierta autonomía, los cuales necesitan de un examen específico. Estos son: individual (el single camorrista), familiar (la familia de Camorra a la que pertenece) y el relacionado con el grupo (pieza intermedia entre los dos primeros). Con respecto a la mutabilidad y la fugacidad de la Camorra napolitana, hay que tener en cuenta que pueden desarrollarse estrategias y objetivos en cada nivel, diferentes e incluso discordantes. ${ }^{37}$

Tan fuerte, en efecto, es el resultado de un cierto carácter "anarquista" napolitano, especialmente en el área efectivamente ciudadana (más que en la provincia o región, donde están presentes grupos con una estabilidad similar a la de algunas conformaciones de Sicilia). Como consecuencia, en el área metropolitana de Nápoles (y, como se ha dicho, sobre todo dentro de los límites de la ciudad) el sistema "Camorra", en su conjunto y también en su configuración individual, obedece a un organigrama más policéntrico que piramidal.

Desde aquí deriva un paisaje criminal inestable y precario, aunque muchas dinámicas se insertan en las huellas de una histórica presencia de familias camorristas, ya que algunas de ellas tienen al menos antepasados del siglo XIX.

Aparece, de todas maneras, un nivel extremo de violencia y un tipo de bruto gangsterismo. A nivel local, la lucha por el poder y el sometimiento del territorio sobre el cual ejercer su actividad delictiva (orientada principalmente a la extorsión y el establecimiento de plazas utilizadas por tráfico de drogas) ${ }^{38}$ parece ser tarada en base a la extensión de la violencia y a la crueldad ejercitada, que pueden parecer no solo desproporcionadas,

37 Véase BRANCACCIO, Luciano: I clan di camorra. Genesi e storia. Donzelli, Roma, 2017. Págs. 124 y ss.

38 Sobre el tema, véase la centralidad de la ciudad de Nápoles en el tráfico mundial de estupefacientes. Por ejemplo, en relación con la presencia de la ciudad en las rutas de drogas con salida desde América Latina (Venezuela, Costa rica, Suriman, Colombia, Ecuador, Perú, Argentina, Brasil), se puede ver SOLÍS DELGADILLO, Juan Mario, MORICONI BEZERRA, Marcelo: "La violencia letal en América Latina: un flagelo heterogéneo pero generalizado". En: Solís Delgadillo, Juan Mario, Moriconi Bezerra, Marcelo (eds.): Atlas de la Violencia en América Latina, Universidad Autónoma de San Luis Potosí, San Luis Potosí, 2018. Págs. 80 y ss. 
sino que también gratuitas. En algunas circunstancias, dentro de una estrategia "para-terrorista", la brutalidad se convierte en la clave de los éxitos criminales, como es evidente en los casos en que algunos asesinos han alcanzado el rango de jefe del grupo. ${ }^{39}$

\section{Crimen organizado, peligro urbano y violencia juvenil.}

Todo esto, le da a Nápoles - ciudad sin duda especial y tan notablemente elaborada en el imaginario común que se ha convertido, en muchas obras "negras", en un "personaje narrativo"-40 un bandidaje violento y criminal de alta peligrosidad social. Este aspecto ha atraído la reacción represiva del poder judicial y de las instituciones que aplican la ley; no obstante, estas acciones no eliminaron el fenómeno criminal en su raíz.

Además, al realizar una represión de los efectos, sin una prevención de las causas, conduce a un nuevo diseño del problema, el cual se manifiesta únicamente en diversas formas. Debe mencionarse, a este respecto, el intento de establecer nuevos centros de poder por las nuevas generaciones de camorristas (o "camorristas-bebé"). De hecho, reacción legal institucional de los últimos años ("post-Gomorra"), junto a las laceraciones que condujeron a las guerras de Camorra, mostraron una situación en la que muchos líderes habían sido asesinados o encarcelados. Esto ha llevado a la sustitución de los roles de liderazgo y al surgimiento de nuevas ambiciones e incontroladas, por parte de jóvenes, a menudo socialmente vinculados con clanes criminales como hijos o nietos de camorristas.

Estos sujetos, que han constituido subjetividades criminales que no pueden reducirse a simples "bandas subculturales de delincuentes", ${ }^{41}$

39 Basta pensar solo en la historia de Setola: "Giuseppe Setola". En: https:// it.wikipedia.org/wiki/Giuseppe_Setola. Además, los eventos de la organización criminal mexicana del Los Zetas parecen emblemáticos.

40 VELÁZQUEZ GARCÍA, Sara: "Muertos que susurran, crímenes en la Italia fascista. El éxito de la mezcla de géneros en la serie El Comisario Ricciardi de Maurizio de Giovanni”. En: Sánchez Zapatero, Javier, Martín Escribà, Alex (eds.): La globalización del crimen. Literatura, cine y nuevos medios. Andavira Editora, Santiago de Compostela, 2017. Pág. 395.

$41 \quad$ Para algunas consideraciones sobre la distinción entre bandas criminales y grupos criminales organizados: KAZYRYTSKI, Leanid: "Criminalidad organizada y bandas juveniles: reflexiones criminológicas sobre la naturaleza de ambos fenómenos". En: Revista de Derecho Penal y Criminología, No 8, 2012. Págs 319 y ss. MEDINA, Juanjo: "Consideraciones criminológicas sobre las bandas juveniles". En: Revista de Derecho Penal y Criminología, $\mathrm{N}^{\circ}$ 3, 2010. Págs. 409 y ss. 
en una ciudad donde la frontera entre los actos de Camorra y los delitos menores no siempre es fácilmente distinguible, han utilizado la ferocidad, los homicidios fáciles, la intimidación en forma de incursiones motorizadas con armas de fuego (llamadas "scese")- ${ }^{42}$ elementos, entonces, vividos casi como una manera "estética" de expresarse- ${ }^{43}$ para consolidar su propia posición, para llegar a un reconocimiento de su subjetividad (en línea con la dinámica consolidada de fascinación por los poderes y las prácticas criminales que sufren muchos jóvenes). ${ }^{44}$

La Camorra, en consecuencia, ha sido liderada, en parte, por jóvenes exaltados que suman las creencias consumistas y comunicativas actuales a la tradicional prevaricación delincuencial. En tal sentido, es posible leer de una manera nueva el tema de la cobertura mediática del crimen organizado (razón por la cual este sufre frecuentemente de una imagen trasmitida por algunos medios). El uso de las redes sociales informáticas para fines promocionales, la particular exterioridad elegida como carácter distintivo, parece proponer de nuevo el tema de la visibilidad del "guappo", por lo que este último tuvo que actuar y aún más mostrarse inequívocamente como tal.

La macro área representada por el plan de acción local de la Camorra siente, así, los cambios de apariencia y sustancia que, no sólo van al unísono

42 Palabra napolitana para «tirado en el suelo». Las acciones se llaman así porque obligan a los que están cerca de yacer en el suelo para evitar chocar con balas pérdidas, disparadas a lo loco. Sobre el fenómeno: VAL, Eusebio: "Vuelve Gomorra". En: https://www.lavanguardia.com/internacional/20150913/54435240477/vuelve-gomorra. html\#ixzz31cQxEoq4. Como evidencia del clamor suscitado por estas acciones, que recuerdan casi las redadas de Far West, extendiéndose la "moda" entre algunos niños "problemáticos" para simular estos actos: "Torre Annunziata, l'ultimo gioco dei piccoli boss: le "finte stese"". En: https://www.ilmattino.it/napoli/cronaca/torre_annunziata_1_ultimo_gioco_dei_piccoli_ boss_le_finte_stese-3473833.html

43

Algunos documentales se refieren principalmente a la situación de la juventud (no solo exactamente de camorra) de lo cual vemos la actualidad y el riesgo de una fascinación por la delincuencia en un territorio donde los jóvenes desfavorecidos parecen carecer de oportunidades reales de trabajo en el desinterés de los servicios sociales y las escuelas. Ver Sciuscià '80 (MARRAZZO, Joe, 1979;) Robinù (SANTORO, Michele, 2016); Largo Barracche (DI VAIO, Gaetano, 2014); Il segreto (CIOP \& KAF, 2013); Ritratti abusivi (MONTESARCHIO, Romano, 2013); Le cose belle (FERRENTE, Agostino, PIPERNO, Giovanni, 2013).

$44 \quad$ Véase: «Muchos de estos jóvenes se suman a la oferta laboral de los grupos delincuenciales que ostentan su poder en símbolos tétricos y que además les ofrece el encanto en la construcción de sus identidades como un mecanismo de empoderamiento machista, que pone en funcionamiento todo tipo de violencias inhumanas e incomprensibles» (LÓPEZ POZOS, Cecilia: "El teatro terrorífico: estrategia de acoso del crimen organizado". En: Visioni LatinoAmericane, 2018, № 18. Pág. 39). 
con la evolución de los núcleos de la Camorra y sus costumbres, sino que también son el resultado de algunos relatos de los medios, para cómo son acogidos ${ }^{45}$ En atención a lo señalado, podríamos decir que estamos en presencia de algún tipo de efecto que podemos llamar "espejo deformante".

Los productos audiovisuales de Gomorra (películas ${ }^{46}$ y series de televisión $)^{47}$ han mostrado una fuerte influencia sobre los usos de las personas, respecto a dinámicas exactamente camorristas ${ }^{48} \mathrm{y}$ emulaciones por parte de la gente "común" (también fuera de la región Campania) ${ }^{49}$

El individualismo generalizado de la Camorra también se ha cruzado con la típica expresión estética de bandas criminales latino-americanas (basta con pensar en los tatuajes como un signo de afiliación) e incluso características estéticas típicas del extremismo islámico (tales como las barbas largas y gruesas: los "Barbudos"). ${ }^{50}$

La música, también, en los territorios donde aparece una ilegalidad generalizada, ha sido en parte afectada por cuestiones pro-delincuencia $\mathrm{y}$ en algunos casos incluso para-camorrista, aunque dentro de algunas canciones neo-melódicas, ${ }^{51}$ narcocorridos y liricas de "maras" hay temáticamente más diferencias que similitudes. ${ }^{52}$

Estos nuevos clanes de "niños" (como han sido nombrados en la prensa) en cierta medida también han afectado a este particular equilibrio de Camorra, entre el aspecto protector y el aspecto intimidante del espacio

45 En general, sobre "mutuos préstamos" entre "realidad" y "ficción", FRANCESCUTTI PÉREZ, Pablo: La pantalla profética: cuando las ficciones se convierten en realidad. Cátedra, Madrid, 2004.

46 (Antes citada).

47 (“Gomorra, La serie". En: https://it.wikipedia.org/wiki/Gomorra_-_La_serie).

48 Ver DE ARCANGELIS, Irene: "La camorra copia la fiction: c'è "Sangue blu" che rivuole Forcella”. En: la Repubblica, edición napolitana, de 30 de enero de 2019.

49 Solo tres ejemplos (uno puramente criminal, los otros dos más apropiadamente culturales): DI FIORE Gigi: "La banda milanese infatuata di Gomorra: per fare le rapine si ispirava alla fiction". En: http://www.ilmattino.it/napoli/cronaca/la_banda_milanese infatuata_di_gomorra2499627.html; NACCARI, Tommaso: "L'influenza di Gomorra sul rap francese". En: https://noisey.vice.com/it/article/rkwxda/gomorra-rap-francese. "L'influence de Gomorra sur le Rap français!". En: https://www.youtube.om/watch?v=3e3WSg28vsc.

50 Sentencia emitida por el juez de la audiencia preliminar Nicola Quatrano del Tribunal de Nápoles en el proceso penal N 3297/15 G.I.P

51 En algunos casos, el estilo y los contenidos de la narrativa cutoliana parecen transponerse en composiciones neomelódicas.

52 PASCALI, Michelangelo: "Malamusica". Neomelodia e legalità. Liguori, Nápoles, 2014. 
de competencia. ${ }^{53}$ A pesar de que esta protección, en verdad, sea dirigida más a los afiliados (pensemos al así llamado bienestar de la Camorra, para cubrir algunos gastos de seguridad social, así como de asistencia legal ${ }^{54}$ que al territorio en su materialidad y sociabilidad (se puede recordar emblemáticamente a la destrucción del ambiente, en la llamada Tierra de Fuegos, en provincia de la ciudad de Caserta). De hecho, hay siempre menos control, por parte del clan, de la "tranquilidad" de lugares donde este mandaba; ya que los asuntos criminales ya no proporcionan, incluso aparentemente, una cierta "cura" del territorio y una (aunque anómala y residual) protección de sus habitantes más cercanos, ${ }^{55}$ cura que, de todos modos, era fuerte sólo en raras y pasadas excepciones. ${ }^{56}$ De acuerdo con lo expresado, prevalece una ilegalidad específica sobre una hipotética "paralegalidad". ${ }^{57}$ Esto no significa, sin embargo, que el fenómeno Camorra se reduzca a una criminalidad únicamente teatral y de "bajo nivel".

Si por un lado la visibilidad es, por lo tanto, un elemento fundamental para la Camorra, otro, igualmente importante, es el ocultamiento en algunos lugares y áreas; $;^{58}$ ya que, en simplificación, por un lado, está la violencia y por el otro el empresariado. Desde un punto de vista determinado, se busca a través del uso de la violencia un aspecto mediático alienante y terriblemente 'bizarro'; y, de otra manera, se siguen discretas lógicas

53 Esto, además, causa una fuerte alarma social, incrementada por las llamadas "pandillas de bebés" (solo parcialmente interpretables de acuerdo con el marco clásico de interpretación del malestar juvenil).

54 A este respecto, COLLETTI, Alessandro: Il welfare e il suo doppio. Percorsi etnografici nelle camorre del casertano. Ledizioni, Milano, 2016.

55 Aunque estos son, en efecto, casi siempre las primeras y principales víctimas de los grupos delictivos.

56 En Forcella (pequeña área del antiguo centro de Nápoles, donde en la segunda parte del Nocento se desarrolló una fuerte presencia de Camorra originalmente basada en el contrabando de cigarrillos), por ejemplo, se respetaba la prohibición de la presencia de droga en el mismo barrio del clan.

57 Dicha paralegalidad es entendida «como un orden paralelo con sus propios códigos, normas y rituales que, al ignorar a las instituciones y al contrato social, se constituyó paradójicamente en un desafío mayor que la ilegalidad»: LÓPEZ POZOS Cecilia: ob. cit. Pág. 37.

58 Con respecto a este aspecto, la definición del Fiscal antimafia de Nápoles, Giovanni Russo, parece ser adecuada, por lo que la Camorra sería como el polvo: está en todas partes, incluso si es difícil ver dónde se coloca. Reportada en PAGANI, Steve: "Camorra clans in control behind Naples facades". En: Reuters del 26 del enero de 1999. 
económico-políticas, las cuales no están extrañas a su común realidad de referencia..$^{59}$

\section{Relaciones "desviadas".}

Las infiltraciones de la Camorra muestran la centralidad de un sistema (complejamente) capilar, donde se ve una mezcla particular de "antiguo" y "moderno". Estas distinciones son particularmente evidentes cuando las camorras se mueven en espacios donde están dirigidas a dedicarse, exclusivamente a los negocios. ${ }^{60}$

En cuanto al nivel de infiltración señalada se asiste, en lugar de una exportación del modelo de control violento del territorio (con algunas excepciones relacionadas a los pocos enfrentamientos de la mafia en el norte de Italia, y por la mayor parte en el extranjero), a una estrategia de inmersión e invisibilidad, más que dirigida a un enraizamiento extraterritorial o a la creación de nuevos grupos con sus grados de autonomía funcional, esta vez gestionada por los intereses de los clanes napolitanos y campanos ${ }^{61}$ (pensar,

59 El temor a las organizaciones criminales a veces, por otra parte, parece no ser generalizado en la imaginación colectiva o, en cualquier caso, que va desvaneciendo a lo largo del tiempo a favor de otras "emergencias". Por ejemplo, refiérase a las cifras porcentaje - presente en la encuesta sobre "la percepción de seguridad de los ciudadanos: más incomodidad, más inseguridad", en EURISPES: Rapporto Italia 2017, "La percezione di sicurezza dei cittadini. Più disagio, più insicurezza", Minerva, Argelato (BO), 2017, pág. 229 - sobre la percepción del poder de las organizaciones criminales entre las principales causas de la propagación de fenómenos criminales en Italia. Mientras que en 2009 el porcentaje fue de $14.7 \%$, en 2017 se redujo a $8.0 \%$, a favor del aumento en otros ítems, incluyendo la "presencia excesiva de inmigrantes".

60 Solo piense que se estima que el $60 \%$ o el $70 \%$ de las empresas que participan en licitaciones públicas son atribuibles a los clanes. Por lo tanto, sería aconsejable establecer una base de datos de todas las empresas participantes, no solo las contratistas, según el Fiscal Nacional de antimafia, Federico Cafiero de Raho, en el informe realizado en la Conferenza nazionale su legalità e sicurezza (Conferencia nacional sobre legalidad y seguridad) celebrada en Nápoles el 16 de noviembre de 2018.

61 Amplius: ALlUM, Felia: The Invisible Camorra. Neapolitan Crime Families across Europe. Cornell University Press, Ithaca-Londres, 2016. 
solo, en los casos ocurridos en España ${ }^{62}$ y Escocia). ${ }^{63}$ Del mismo modo, las acciones de reciclaje no están dirigidas casi nunca a la reconversión "subjetiva" total.

Concluyendo esta reflexión, las evoluciones de la Camorra a las cuales nos hemos referido, no deben ser vistas como una discontinuidad total respecto al modelo de actuación camorrístico; pero, por lo menos en profundidad, como formas de ajuste, que no niegan el modus operandi a la base del ideal tipo de camorrista (sobre el cual la ley represiva fue modelada). Tales dinámicas, para ser posibles, necesitan, de todas maneras, de específicas experiencias y competencias profesionales además de complicidad local.

Por esta razón, en los nuevos territorios, se puede también observar la existencia de relaciones "desviadas" con ciertos sectores de la sociedad y parte de la economía legal local, pero con diferentes modalidades. ${ }^{64}$

Desde esta mirada, pasando a una definición menos circunscrita, debe rechazarse la tesis que ve en las formas de crimen organizado camorrísticomafioso un cuerpo extraño frente a la sociedad más general (conforme a la teoría clásica de América del Norte sobre la mafia como "invasión alienígena" contra una sociedad por lo demás sana). ${ }^{65}$ Así que, hay una concepción "médico-social" que teoriza meras soluciones sectoriales

62 Sobre la preferencia de los camorristas por España, que sería el País más vinculado a la Camorra después de Italia: FARANO, Adriano: "Roberto Saviano: «La Spagna? Per la Camorra è Costa nostra»". En: https://cafebabel.com/it/article/roberto-saviano-la-spagnaper-la-camorra-e-costa-nostra-5ae004fcf723b35a145dc889/. SAINI, Valentina: "Catamorra, come le mafie hanno colonizzato la Catalogna". En: https://www.glistatigenerali.com/ criminalita_napoli/catamorra-come-le-mafie-hanno-colonizzato-la-catalogna/.

63 Una de las fortalezas de la camorra es Aberdeen, donde un escocés se afilió formalmente a la camorra disfrutando de todos sus privilegios: DELL'ARTI, Giorgio: "Biografia di Augusto La Torre". En: http://cinquantamila.corriere.it/storyTellerThread. php?threadId=LA\%20TORRE\%20Augusto; "Affari ad Aberdeen: la Scozia diventa l'Eldorado della camorra". En: https://www.ilmattino.it/napoli/cronaca/affari_ad_aberdeen_ la_scozia_diventa_39_eldorado_camorra-556274.html.

$64 \quad$ Véase LAMBERTI, Amato: La camorra. Evoluzione e struttura della criminalità organizzata in Campania. Boccia Editore, Salerno, 1992, passim. Acerca de un caso específico: MARTONE, Vittorio: "La camorra come stakeholder nella governance del territorio". En: Meridiana. Rivista di Studi Storici e Sociali, № 73, 2012. Págs. 103 y ss.

65 Sobre la Alien Conspiracy Theory, SMITH, Dwight C. Jr.: "Mafia: The Prototypical Alien Conspiracy". En: Annals of the American Academy of Political Science and Social Science, vol. 423, 1976. Págs. 75 y ss.; ID.: "The Alien Conspiracy Theory: aka The Elephant in the Front Parlor". En: The European Review of Organised Crime, $\mathrm{N}^{\circ} 3(1)$, 2016. Págs. 50 y ss. 
como instrumentos decisivos para resolver el problema. Tanto esta visión como aquella (a menudo conectada) que, exasperando su carácter extraño, "fantasmizza" el fenómeno de la mafia (llegando a postular su impenetrabilidad y profunda incognoscibilidad, con respecto a su génesis, articulación y dialéctica interna, para una total diferencia básica entre nosotros y ellos $)^{66}$ y corre el riesgo de tener que concentrarse demasiado en los efectos y no en las causas de la misma, parecen que, cuando están absolutamente generalizados, descansar sobre fundamentos científicos y reales débiles.

Esto, entonces, no solo es cierto bajo un perfil cultural (ya que es fácil ver la homogeneidad de los valores, especialmente en relación con los de una sociedad de consumo que se basa en el dinero, la importancia y el reconocimiento social), sino también en la medida que hace difícil pensar a un fenómeno tan grande y de larga duración sin ninguna relación - entendida además como nexos sinérgicos - con las instituciones legales. La importancia de "infiltrarse" - un verbo que tiene cierta ambigüedad, que llama al avance de una fuerza externa y, sugestivamente, casi de una enfermedad - en las instituciones tiene que ser relacionada (así como con ciertas dificultades de prevención administrativa y represión penal del fenómeno ${ }^{67}$ con el interés de algunas partes de aquellas instituciones en "hacerse infiltrar". ${ }^{68}$ Se ha señalado que en la historia de la Camorra es más frecuente identificar los casos en que el poder institucional ha necesitado de la Camorra que al contrario. ${ }^{69}$ (De manera correspondiente, en algunos países de América Latina, la presencia y, a veces, la potencia extrema de traficantes de droga se apoya no sólo a la ineficacia de la represión y, de manera más general, sobre la incapacidad de la sociedad de prevenir

66 LOMBARDI SATRIANI, Luigi M.: "En torno a la mafia”. En: Cámara de Landa, Enrique, Morabito, Stefano (eds.): ob. cit. Pág. 45.

67 En relación con algunos problemas en la aplicación de la legislación interna para combatir la infiltración de la mafia en organismos públicos locales: PRIOLO, Giuseppe: "Legislación italiana de lucha contra las infiltraciones de la mafia en las Instituciones". En: Cámara de Landa, Enrique, Morabito, Stefano (eds.): ob. cit. Págs. 141 y ss.

68 Como evidencia de la centralidad del plan administrativo institucional en los proyectos de la mafia (que incluía tanto las hipótesis de administraciones "ocupadas" por clanes como las hipótesis de administraciones que están de acuerdo con los clanes), recientemente se han previsto algunas extensiones operativas de ciertas reglas originalmente concebidas para contrarrestar a la mafia en casos de crímenes contra la administración pública.

69 COMMISSIONE PARLAMENTARE ANTIMAFIA (COMISION PARLAMENTARIA ANTIMAFIA): Camorra e politica. Laterza, Roma-Bari, 1994. Pág. 21. 
eventos delictivos tan extensos, sino que también en algunas complicidades precisas por segmentos, incluso apicales, de las instituciones).

La metáfora del "pulpo", para representar la esencia y la acción de la mafia (imagen que, sin embargo, normalmente se utiliza para la Mafia siciliana, pero utilizada por primera vez en ocasión del maxi-juicio contra la Camorra hace más de un siglo), ${ }^{70}$ es, por lo tanto, siempre inadecuada si la mafia y la camorra se consideran separadas de la sociedad. Aunque el carácter sistémico de la Camorra (deliberadamente, quizás de manera veleidosa o arbitraria), destaca también en la forma en que actualmente se llama: "Sistema"; ya que la capacidad sistémica no significa necesariamente independencia desde las instituciones legales y la oposición pura y simple a estas, incluso del Estado. ${ }^{71}$

Refiriéndose al paradigma de la complejidad, ${ }^{72}$ para identificar la extensión de los fenómenos mafiosos, y también al uso de algunas de las prescripciones de las teorías sobre las redes; la relación entre el Estado y la mafia aparece mucho más compleja.

En estos términos, además, la evolución (o involución) de la sociedad, conduce a una mutación en las relaciones entre estos fenómenos criminales y las instituciones.

Refiriéndose de nuevo, específicamente, a la situación italiana, podemos ver, por ejemplo, cómo ha cambiado la relación con las instituciones, a raíz de la introducción de la llamada "Segunda República", cuando los escándalos de corrupción generalizados llevaron al nacimiento de una nueva clase política ("post-Tangentópolis"). ${ }^{73}$ Esto, junto con las reformas para descentralizar el poder administrativo ha supuesto, paradójicamente, que en algunas ocasiones fuera más fácil actuar ilícitamente, a través de amenazas y acuerdos con los nuevos actores a cargo de la gestión

$70 \quad$ Nos referimos al famoso proceso "Cuocolo", celebrado en 1911 y 1912. Sobre la cronología y la ambigüedad del juicio, viciado por distorsiones de investigación y presiones institucionales, MARVASI, Roberto: La tragedia Cuocolo: governo, polizia e camorra. Edizioni di Scintilla, Nápoles, 1907; DE JACO, Aldo: Napoli monarchica, milionaria, repubblicana. Newton Compton, Roma, 1982. Págs. 74 y ss.; BARBAGALLO, Francesco: Storia della camorra. Laterza, Roma-Bari, 2010. Págs. 90 y ss.

71 La Camorra, a diferencia de Cosa Nostra, nunca se ha opuesto a un orden alternativo al del Estado, gobernando, en cambio, el "desorden social": COMMISSIONE PARLAMENTARE ANTIMAFIA: ob. cit. Pág. 21.

72 SANTINO, Umberto: La mafia interpretata. Dilemmi, stereotipi, paradigmi. Soveria Mannelli, Catanzaro, 1995. Pág. 130.

73 Proceso de investigación sobre la corrupción de los políticos italianos de los años '90. 
política y administrativa ${ }^{74}$ (que a nivel local se presentaban políticamente menos fuertes y administrativamente menos estables), en particular para drenar el dinero público. Un cambio más general en las formas de política parece haber conducido a un nuevo modelo de política, cada vez más potencialmente comprometido con poderes territoriales que no son necesariamente legales. ${ }^{75}$

El problema de las camorras y las mafias, por lo tanto, abordándolo como problema interno, es también un problema específico de una parte de las instituciones y sus responsabilidades omisivas y comisivas.

\section{Cuestiones reglamentarias.}

Junto a esto, hay además elementos problemáticos, estos a veces también resultado de la intencionalidad política y económica, otras veces debido a imposibilidades objetivas, a la dificultad para mantenerse al día con los cambios de las innovaciones tecnológicas y criminales o a inadecuaciones especificas.

Por lo que, tiene que ver con la voluntad no represiva, podemos referirnos a las facilidades en el reciclaje, a la base de muchos enfoques (sustancialmente o aparentemente) neoliberales, donde la libre circulación de dinero triunfa sobre la salvaguardia sustantiva de las sociedades constitucionales y de sus valores; no solamente unas pocas veces, sobre el respeto directo o indirecto de los derechos humanos. Nos referimos a los "refugios fiscales", ${ }^{76}$ a la ausencia de cooperación de algunos países contra el lavado de dinero, ${ }^{77}$ así como a los controles deficientes en el flujo de riquezas en algunas de las bolsas más importantes del mundo. Pero también se refleja, con un poco de sospecha razonable, en las negaciones de muchos países, en primer lugar, europeos, de la presencia de mafias, sólo por la

$74 \quad$ Además, esta situación facilita el intento de los camorristos de ser elegidos como representantes políticos. Sobre el tema, se informa que hubo un número muy altode candidatos con antecedentes penales en las elecciones de 1992 en BEHAN, Tom: See Naples and Die. The Camorra Organized Crime. Tauris, Londres, 2002.

75 BRANCACCIO Luciano: "Mafia Capitale: associazione mafiosa e fazione

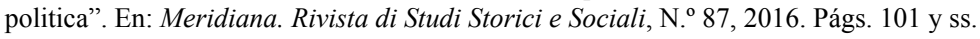

76 Todavía se defienden como lugares necesarios y "correctos" para la economía (FISHER, Peter A.: "È sbagliato demonizzare". En: Internazionale del 10/16 de noviembre de 2017, N 1230. Pág. 107).

77 CARMONA, Angelo: Premesse a un corso di diritto penale dell'economia. Mercato, regole e controllo penale nella postmodernità. Cedam, Padua, 2002. Pág. 64. 
razón que el aspecto de la extorsión y de la violencia está ausente o (en efecto) bien cubierto. ${ }^{78}$

Todo esto tiene, como es lógico, reflejos en la esfera normativa.

Nos encontramos aquí con cuestiones normativas italianas (piénsese en la declinación histórica y sociológica del delito de asociación mafiosa, ${ }^{79}$ lo que ha dado lugar a una oscilación con respecto a la aplicación de este delito durante el reciente proceso de "Mafia Capital", ${ }^{80}$ sobre una organización ilícita en Roma, ${ }^{81}$ así como los intentos interpretativos de indebida ampliación del caso, ${ }^{82}$ de acuerdo con una extensa lógica que ya había tocado el caso del concurso externo en la asociación mafiosa), ${ }^{83}$ que no siempre logran seleccionar adecuadamente los fenómenos sancionables

$78 \quad$ Mientras los eventos dramáticos manifiestan una voluntad innegable; nos referimos, por ejemplo, a la famosa masacre de la 'ndrangheta de 2007 en Duisburg, Alemania; también recuerde las protestas posteriores contra la extorsión, que llevaron al descubrimiento de muchas extorsiones de la camorra en Alemania. Ver, por ejemplo, GARAVINI, Laura: "Mafia? Nein danke! - La più grande ribellione al pizzo fuori dall'Italia". En: https:// mafianeindanke.de/mnd-storia/.

79 Más precisamente, para una distinción entre el modelo legal punitivo y la interpretación histórico-sociológica de la asociación mafiosa, DALLA CHIESA, Nando: "A proposito di Mafia Capitale. Alcuni problemi teorici". En: Rivista di Studi e Ricerche sulla criminalità organizzata, $\mathrm{N}^{\circ} 2,2015$. Págs. 1 y ss.

80 Se excluyó tal imputación en el resultado de la sentencia de primera instancia y, en cambio, se reconoció en el grado de apelación. Finalmente, la Corte Suprema di Cassazione (Tribunal Supremo de Casación) descartó la existencia de este cargo, cancelando, en esta parte, la sentencia de apelación sin remisión Sobre la cuestión, entre otros, FORNARI, Luigi: "Il metodo mafioso: dall'effettività dei requisiti al 'pericolo d'intimidazione' derivante da un contesto criminale? Di 'mafia' in 'mafia', fino a 'Mafia Capitale". En: Diritto penale contemporaneo, 2016. Págs. 1 y ss., en https://www.penalecontemporaneo. it/upload/1465420783FORNARI_2016a.pdf. Ver también AA. VV.: Mafia Capitale. En: Meridiana. Rivista di Studi Storici e Sociali, № 87, 2016.

81 Ver TRIBUNALE DI ROMA: "Ordinanza sull'applicazione delle misure cautelari - procedimento penale $\mathrm{N}^{\circ}$ 30546/10 R.G.N.R." (TRIBUNAL DE ROMA: “Ordenanza sobre la aplicación de medidas cautelares - procedimiento penal $\mathrm{N}^{\circ} 30546 / 10$ R.G.N.R"), 28 de noviembre de 2014. Legible en: https:/www.giuliocavalli.net/wp-content/uploads/2014/12/ ORDINANZA-MONDO-DI-MEZZO.pdf.

82 POMANTI, Pietro: "Principio di tassatività e metamorfosi della fattispecie: l'art. 416 bis c.p.". En: Archivio penale, 2017, en http://www.archiviopenale.it/File/ DownloadArticolo? codice=1c733dec-05c5-487a-b858-6497c213de53\&idarticolo=15089.

83 Véase FIANDACA, Giovanni: "Il concorso esterno tra guerre di religione e laicità giuridica". En: Diritto penale contemporanteo, 2012, Págs. 253 y ss., en https://www.penalecontemporaneo.it/ upload/1331919165Fiandaca\%20su\%20processo\%20DellUtri.pdf. Y FORNARI, Luigi: "Il principio di tassatività alla prova della "lotta" alla mafia: contiguità e metodo mafioso". En: Cocco, Giovanni (ed): Trattato breve di diritto penale. Temi contemporanei. Per un manifesto del neoilluminismo penale. Cedam, Padua, 2016. Págs. 289 y ss. MANNA, Adelmo: "L'ammissibilità di un c.d. concorso "esterno" nei reati associativi, tra esigenze di politica criminale e principio di legalità". En: Rivista italiana di diritto e procedura penale, 1994. Págs. 1189 y ss. 
y que a veces surge como una hipótesis de conflicto entre el "derecho legislativo" y el "derecho jurisprudencial", ${ }^{84}$ así como con disputas sobre reglamentos extranjeros (basadas principalmente en la falta deliberada de infracción por asociación de mafia, porque se considera ilógica, "injusta" la represión de un simple deseo de cometer un delito), lo que lo hace menos atacable fenómenos ilícitos transnacionales ${ }^{85}$ Los problemas consiguientes surgen con respecto a las investigaciones de estos asuntos en otros territorios (si tal crimen falta, es obviamente imposible actuar). Esto, sin embargo, aparece también como un reflejo problemático de una sensibilidad directa psicológicamente a negar la existencia del problema de la Camorra y la Mafia (como indirectamente testifican las deficiencias investigativas en algunas regiones del centro y norte de Italia). ${ }^{86}$

Esto condujo también a incertidumbres sobre la recogida de datos y la consideración de la presencia de la Camorra, que generalmente surge sólo como "emergencia local", debido al fuerte impacto ("impactividad") y a la visibilidad de esta violencia, presente en algunas regiones y ausentes en otras. ${ }^{87}$ Además, téngase en cuenta que incluso la mayor capacidad de contraste, tal como se desarrolló territorialmente, implica que en algunas áreas los casos de delincuencia organizada (así como la corrupción) emergen más y, por esto, son considerados, comparativamente, tan predominantes. (También está claro que cuanto más se considera un lugar "libre" de la infiltración de la mafia y, por tanto, no se proporciona los medios adecuados de prevención y represión, mayor es el riesgo de dejarlo más indefenso).

84

PALAZZO, Francesco: "Legalità penale: considerazioni su trasformazione e complessità di un principio 'fondamentale"'. En: Quaderni fiorentini per la storia del pensiero giuridico moderno, vol. XXXVI, 2007. Págs. 1279 y ss. GARGANI, "Verso una 'democrazia giudiziaria'? I poteri normativi del giudice tra principio di legalità e diritto europeo". En: Criminalia. 2011. Págs. 99 y ss.

85 Esto, a pesar de la firma de la Primera Convención de la ONU sobre la Delincuencia Organizada Transnacional firmada en Palermo. Con respecto a la importancia de dicha represión, también se mencionan los contactos entre la Camorra y el terrorismo internacional (por ejemplo: DI MARCO, Emiliano: "I collegamenti tra camorra e jihad islamica. Napoli crocevia dei traffici e base logistica". En: https://www.agoravox.it/I-collegamenti-tracamorra-e-jihad.html).

86 Si por el d.lgs. de junio de 1992, convertido en 1. 356/1992, se han establecido fiscales nacionales contra la mafia y fiscales antimafia, que no siempre han podido responder plenamente a su función. Sobre la expansión territorial de las organizaciones criminales del sur de Italia, SCIARRONE, Rocco (ed.): Mafie del Nord. Strategie criminali e contesti locali. Donzelli, Roma, 2014.

87 PASCALI, Michelangelo: "Le camorre tra esibizione di violenza e occultamento degli affari”. En: Diritto e giustizia minorile, N. ${ }^{\circ} 1-2,2016$. Págs. 61 y ss. 
Ahora se destaca la clasificación de las redes criminales como actores malévolos de las relaciones internacionales. ${ }^{88} \mathrm{Y}$, dentro del problema de las expansiones de la mafia en el extranjero, ${ }^{89}$ la Camorra se puede considerar entre esas "sociedades criminales" perfeccionadas tanto a nivel local que pueden proyectarse a través de la frontera,,$^{90}$ en ámbito tanto europeo como extraeuropeo. ${ }^{91}$ De hecho, esta también está bien adaptada a los grandes procesos de la contemporaneidad y las consiguientes mutaciones, con la creación de "zonas de libre comercio", utilizando habilidades y fuertes relaciones de intercambio a nivel internacional ${ }^{92}$ que apoyan su mayor propagación. ${ }^{93}$ Los que parecían atados, entonces, demostraron ser puntos fuertes. Su tradicional falta de centralización le ha permitido resistir más a los ataques judiciales y aprovechar las nuevas oportunidades en los mercados económicos y financieros. ${ }^{94}$ El reconocimiento del peligroso poder criminal de los camorristos aparece, además, establecido en el lado opuesto del océano (en comparación con los lugares de nacimiento

$88 \quad$ WITKER, Iván: 'De Lucky Luciano al 'chapo' Guzmán. Las redes criminales como actores malévolos de las relaciones internacionales". En: Sampó, Carolina, Troncoso, Valeska (eds.): El crimen organizado en América Latina: manifestaciones, facilitadores y reacciones. Instituto Universitario General Gutiérrez Mellado de Investigación sobre la Paz, la Seguridad y la Defensa, Madrid, 2017. Págs. 71 y ss.

89 DAGNES, Joselle, DONATIELLO, Davide, SCIARRONE, Rocco, STORTI, Luca: "Le mafie italiane all'estero: un'agenda di ricerca". En: Meridiana. Rivista di Studi Storici e Sociali, N. ${ }^{\circ} 87,2016$. Págs. 149 y ss.

90 CORNEJO, Abel: Asociación ilicita. Ad-hoc, Buenos Aires, 1992. Pág. 21.

91 PISANI, Mario: "Criminalité organisée et coopération internacionale". En: Gutiérrez-Alviz Conradi, Faustino, Valcárcel López, Marta (eds.): La cooperación internacional frente a la criminalidad organizada. Universidad de Sevilla. Secretariado De Publicaciones, Sevilla, 2001. Pág. 60.

92 Entre otras cosas, parece ser muy activa en los sectores del contrabando de tabaco y productos y prendas falsificados y en la actividad de acuñación y distribución de dinero falso, con contactos cercanos con sujetos de muchos Países (incluyendo China), gracias también al papel central desempeñado por el puerto de Nápoles: GIMÉNEZ-SALINAS FRAMIS, Andrea: "La delincuencia organizada en Europa: extensión, factores facilitadores y rasgos principales". En: CENTRO SUPERIOR DE ESTUDIOS DE LA DEFENSA NACIONAL: La lucha contra el crimen organizado en la Unión Europea, Ministerio de Defensa, España, 2012. Pág. 30.

93 BLANCO CORDERO, Isidoro: "Principales instrumentos internacionales (de Naciones Unidas y la Unión Europea) relativos al crimen organizado: la definición de la participación en una organización criminal y los problemas de la aplicación de la Ley Penal en el espacio". En: AA. VV.: Criminalidad organizada. Reunión de la sección nacional española preparatoria del XVI Congreso de la AIDP en Budapest. Gabinete del Rector de la Universidad de Castilla-La Mancha, Ciudad Real, 1999. Págs. 19 y ss.

94 CURBET, Jaume: La glocalización de la (in) seguridad. Plural, La Paz, 2006. Pág. 22. 
de los grupos de Camorra).$^{95}$ Claramente, no estamos hablando aquí simplemente de "brotes" en otros territorios de organizaciones del mismo molde, pero esencialmente autónomas, ${ }^{96}$ sino más bien de estrategias válidas de verdadera internacionalización, tanto que se ha afirmado que la Camorra forma dramáticamente parte, incluso con sus tácticas atípicas, de las (pocas) grandes organizaciones globales del crimen organizado de la matriz mafiosa.${ }^{97}$ En consecuencia, una respuesta represiva transnacional seria parece necesaria, ${ }^{98}$ también en vista de los métodos sin precedentes de irregularidades provocados por los nuevos medios tecnológicos, ${ }^{99}$ acelerando los aspectos inevitables de la internacionalización del derecho penal, especialmente en el campo de la economía criminal, ${ }^{100}$ y preparando medios internacionales armoniosos de amplio contraste que pueden, entre

95 Por ejemplo, SAVIANO, Roberto: "Il potere della camorra a stelle e strisce. I Casalesi alla conquista dell'America". En: la Repubblica, edicion napolitana, de 29 de julio de 2011. Y DI MEO, Simone: "Chi sono i cinque camorristi nel mirino dell'intelligence Usa". En: Il Sole 24 ore de 6 de agosto de 2013.

96 Por ejemplo, sobre la "Camorra de Nueva York", también llamada "Camorra de Brooklyn", activa a principios del siglo XX en los Estados Unidos de América, que incluía múltiples grupos, algunos de los cuales entre ellos la "Neapolitan Navy Street Gang" y la "Neapolitan Coney Island Gang", compuestas por una mayoría de miembros nacidos en territorio estadounidense, "Camorra newyorkese". En: https://it.wikipedia.org/wiki/Camorra newyorkese. Y "1900 i grandi camorristi di New York: la Brooklyn Camorra". En: https:// pulcinella291.forumfree.it/?t=69888728. Sulla relazione tra questa e i coevi gruppi mafiosi siciliani sorti nel medesimo territorio, MOTTOLA, Giorgio: Camorra nostra. Nascita di una S.p.a. del crimine. Sperling \& Kupfer, Milano, 2017. Pág. 35.

97 GAYRAUD, Jean-François: El G9 de las mafias en el mundo. Geopolitica del crimen organizado. Tendencias, España, 2007. Págs. 98 y ss. El autor afirma que, para llamarse "mafia", una organización debe consistir en una sociedad secreta y fraterna de carácter criminal, permanente y jerárquico, basada en la obediencia, el reclutamiento étnico, el control de un territorio, el dominio de otras realidades criminales y edificada sobre una mitología específica.

98 GÓMEZ DE LIAÑO FONSECA HERRERO, Marta: Criminalidad organizada y medios extraordinarios de investigación. Colex, Madrid, 2004. Págs. 31 y ss. Véase, también, LÓPEZ BARJA DE QUIROGA. Jacobo: "Posición de la Unión Europea sobre el crimen organizado". En: Granados Pérez, Carlos (ed.): La criminalidad organizada. Aspectos sustantivos, procesales y orgánicos. Consejo General del Poder Judicial, Madrid, 2001. Págs. 113 y ss.

99 RUIZ RODRÍGUEZ, Luís Ramón, GONZÁLEZ AGUDELO, Gloria: "El factor tecnológico en la expansión del crimen organizado". En: Puente Aba, Luz María, Zapico Barbeito, Mónica, Rodríguez Moro, Luis (eds.): Criminalidad organizada, e inmigración. Retos contemporáneos de la política criminal. Comares, Granada, 2008. Págs. 1 y ss.

100 CESANO, José Daniel: "Criminalidad Económica e Internacionalización del Derecho Penal: experiencias en la Unión Europea y en el Mercosur”. En: Revista Internacional Derecho Penal Contemporáneo, Nº. 24, 2008. Págs. 57 y ss. 
otras cosas, evitar el uso estratégico de estas organizaciones criminales de los intersticios de menores o no punibilidad derivados por la llamada práctica de "jurisdicción hopping" 101 y por la presencia de una potencial "legislación favorable" 'ofrecida' por el "mercado de leyes" en los tiempos de la globalización. ${ }^{102}$

Obviamente, en todo esto, el peligro opuesto es considerar la existencia en todas partes de las formas de Camorra y considerar cada caso de malversación o cualquier comportamiento, no solo criminal, sino también solamente éticamente censurable, como (índice de) un acto de mafia. ${ }^{103}$

Solamente una mención sobre el problema del uso de bienes confiscados. Actuar sobre la riqueza acumulada por la Camorra parece ser un arma muy útil, golpearlo en el nivel de su prestigio social ("el crimen no compensa") y organizativo (a menudo es más fácil reemplazar a un afiliado que a un bien). Más allá del problema, no solo italiano - por supuesto -, de identificación de bienes adquiridos a través de fuentes de origen ilícito $\mathrm{y}$ las formas precisas en que se han constituido irregularmente, ${ }^{104}$ así como la formación y el mantenimiento de la prueba de todo esto en el juzgado, ${ }^{105}$ la inadecuada o mala administración de los bienes incautados, ${ }^{106}$ en parte

101 CASELLI, Carlo: "Los instrumentos internacionales en la lucha contra el crimen organizado". En: Cámara de Landa, Enrique, Morabito, Stefano (eds.) : ob. cit. Págs. 192 y ss. 102 CENTORRINO, Mario: "Criminalidad Transnacional y Procesos de Globalización”. En: Cámara de Landa, Enrique, Morabito, Stefano (eds.) : ob. cit. Pág. 187. 103 Ver VISCONTI, Costantino: "La mafia è dappertutto": Falso! Laterza, RomaBari, 2016.

104 DURRIEU FIGUEROA, Roberto: La ganancia económica del delito. Lavado de dinero, decomiso y financiamiento del crimen organizado y del terrorismo. Marcial Pons Argentina, Buenos Aires, 2017. Págs. 29 y ss.

105 PÉREZ CEBADERA, María Ángeles: "La prueba del origen ilícito de los bienes y el decomiso ampliado". En: González-Cuéllar Serrano, Nicolás, Sanz Hermida, Ágata María, Ortiz Pradillo, Juan Carlos (eds.): Problemas actuales de la justicia penal. Colex, Madrid, 2013. Págs. 365 y ss.

106 Sobre los problemas a este respecto: CORTE DEI CONTI, SEZIONE CENTRALE DI CONTROLLO SULLA GESTIONE DELLE AMMINISTRAZIONI DELLO STATO: "L'amministrazione dei beni sequestrati e confiscati alla criminalità organizzata e l'attività dell'agenzia nazionale (ANBSC). Deliberazione 23 giugno 2016, $\mathrm{n}$. 5/2016/G” (TRIBUNAL DE CUENTAS, SECCIÓN DE CONTROL CENTRAL SOBRE LA GESTIÓN DE LAS ADMINISTRACIONES ESTATALES: "La administración de los activos incautados y confiscados del crimen organizado y la actividad de la agencia nacional (ANBSC). Resolución 23 de junio de 2016, 5/2016/G”). En: http://www.corteconti. it/export/sites/portalecdc/_documenti/controllo/sez_centrale_controllo_amm_stato/2016/ delibera_5_2016_g.pdf. Además, en NOVI Errico: “"L'Agenzia nazionale incapace di gestire le aziende sequestrate»”. En: Il dubbio de 11 de abril de 2018, el Fiscal General de Roma 
debido a una cierta ideologización de la legislación pertinente italiana (estos bienes no deberían producir beneficios económicos directos, sino que una "utilidad social", ${ }^{107}$ y no pueden ser generalmente enajenados, a menos que los bienes inmuebles sea incompatibles con los fines de interés público, ${ }^{108}$ ya que pudiera suceder que los mismos delincuentes realicen la compra de los mismos) es, ${ }^{109}$ sin duda, uno de los aspectos particularmente contraproducentes. Por otra parte, las ganancias ilegales del clan a menudo se mueven hacia los Países donde la represión de la mafia es más débil y, por lo tanto, es más difícil actuar para la incautación y confiscación de estos bienes. ${ }^{110}$

destaca la estructura todavía no del todo adecuada de la Agencia para los bienes confiscados (y condena, en algunos casos, el uso de "medidas paralelas" en detrimento de la justicia ordinaria). Claramente, no administrar adecuadamente los activos confiscados parece ser la peor imagen que el estado puede dar al respecto.

107 Hay, sin embargo, ejemplos virtuosos. Véase, por ejemplo, la gestión del fondo rústico “Amato Lamberti" ("Fondo Rustico Amato Lamberti”. En: https://it-it.facebook.com/ Fondo-Rustico-Amato-Lamberti-368044103267539/), óptimo tanto desde el punto de vista económico como a los efectos beneficiosos de la relación con el territorio.

108 Cabe señalar, de todos modos, que recientemente la Ley 17 de octubre de 2017, $N^{\circ} 161$, y el Decreto Ley 4 de octubre de 2018, $\mathrm{N}^{\circ} 113$, socavaron parcialmente el "dogma" de la no venta general de tales activos. Específicamente, se amplió la audiencia de compradores potenciales de activos cuya naturaleza es incompatible con un destino de servicio público, yendo a prever, además de los entes locales, cooperativas de construcción compuestas por personal de las Fuerzas Armadas o Fuerzas de Policía, organismos públicos que tienen, entre otros fines institucionales, también la inversión en el sector inmobiliario, asociaciones profesionales, que aseguran mayores garantías y utilidad para la búsqueda del interés público y a las fundaciones bancarias, también a cada "mejor postor" (siempre que haya una certificación especial antimafia emitida sobre la base de Base de datos nacional única de la documentación antimafia). No obstante, estas extensiones siguen siendo objeto de duras críticas. Por ejemplo, "Decreto sicurezza: Libera, "stop a vendita dei beni immobili confiscati ai privati"”. En: https://www.agensir.it/quotidiano/2018/11/27/decreto-sicurezza-libera-stopa-vendita-dei-beni-immobili-confiscati-ai-privati/?PageSpeed=noscript.

109 Contra: TOSCANO, Salvo: "Il procuratore nazionale antimafia: «Sì alla vendita dei beni confiscati»". En: http://ivesicilia.it/2017/02/28/11-procuratore-nazionale-antimafiasi-alla-vendita-dei-beni-confiscati_831385/.

110 En términos más generales, incluso las diferentes disposiciones procesales pueden favorecer la vida de los clanes. Por ejemplo, la imposibilidad de realizar un juicio penal en ausencia del imputado, la ausencia de concesiones de extradición hasta el año 2000, la ausencia del crimen de asociación mafiosa (con la introducción solo en el año 2010 del crimen de asociación criminal) ha contribuido al hecho de que España se convirtió en algunos momentos en un destino favorito para los afiliados de la Camorra. 
Solo piense que los equipos de Camorra son, entre las mafias italianas, los más proyectados hacia inversiones en la economía legal fuera del área de origen y en Europa. ${ }^{111}$

Si las camorras prosperan, también gracias a la ayuda de un "área gris" 112 (un espacio intermedio entre la legalidad y la ilegalidad), los estrictos límites del delito de "participación externa" a la mafia (cuando no se dilatan inapropiadamente, también gracias a su posible confusión con otros tipos de delitos) ${ }^{113}$ excluyen muchas situaciones, para usar un eufemismo, "ambiguas". Sobre esto, ciertamente no ayuda la resistencia de algunos gremios profesionales a las predisposiciones de controles transparentes y ciertas sanciones a los miembros, en la búsqueda de la autorregulación sostenible. ${ }^{114}$ Además, el desenfoque gradual de la línea entre el crimen

111 SAVONA, Ernesto, RICCARDI, Michele (eds.): From illegal markets to legitimate businesses: the portfolio of organised crime in Europe. Final Report of Project OCP - Organised Crime Portfolio. Transcrime, Trento, 2015. Págs. 161 y ss.

112 Ver, emblemáticamente, BIANCONI, Giovanni: "«Non serve gente che spara, meglio chi sa usare la Rete». Gli affari dei clan con i giochi”. En: Corriere della Sera de 15 de noviembre de 2018. La intercepción reportada en el artículo muestra que el "índice" que buscan los líderes de la delincuencia organizada del tipo mafioso es, cada vez más, lo que hace que el ratón del ordenador se mueva (y hace "pin pin!"), no el que presiona el disparador de una pistola (y hace "bam bam!"). Además, hay una tendencia en las familias mafiosas, apoyada por mujeres, de la "exfiltración" de las nuevas generaciones de los aspectos puramente "militares" de los clanes a favor de la realización de su propio camino entre grupos profesionales de "cuello blanco": ZINITI, Alessandra: "E ora le donne di mafia allevano colletti bianchi. Come cambia la strategia dei clan". En: la Repubblica del 28 de enero de 2019.

113 Véanse también: DE FRANCESCO, Giovannangelo: "Societas sceleris. Tecniche repressive delle associazioni criminali". En: Rivista italiana di diritto e procedura penale, 1992. Págs. 54 y ss. CAVALIERO, Antonio: "Il concorso eventuale nel reato associativo. Le ipotesi delle associazioni per delinquere di tipo mafioso", Esi, Nápoles, 2003. PALMA, Alessandra: "Il controverso istituto del concorso esterno nei reati associativi". En: Studium iuris, 2006. Págs. 1449 y ss. FIANDACA, Giovanni: "Il concorso 'esterno' tra sociologia e diritto penale". En: Foro italiano, 2010, Vol. V. Págs. 176 y ss. MAIELLO, Vincenzo: Il concorso esterno tra indeterminatezza legislativa e tipizzazione giurisprudenziale. Giappichelli, Turín, 2014.

114 D'ALFONSO, Stefano: "Professioni liberali e area grigia. Per un'antimafia degli ordini professionali". En: Brancaccio, Luciano, Castellano, Carolina (eds.): Affari di camorra. Famiglie, imprenditori e gruppi criminali. Donzelli, Roma, 2015. Págs. 211 y ss. 
económico y financiero y el crimen organizado de carácter mafioso ha requerido una comparación general ${ }^{115}$ entre los paradigmas respectivos. ${ }^{116}$

Decíamos sobre la sinergia necesaria, entre acciones preventivas y acciones represivas; sin embargo, el aspecto represivo tiene también algunas dificultades en relación a la singularidad de la Camorra.

Confirmando lo antes dicho, la Camorra napolitana parece estar caracterizada por la presencia de un nivel "alto" y un nivel "brutal", mostrando ciertas características sistémicas que tienen que ser comparadas con la pauta reguladora que debe ser utilizada para fines punitivos.

En relación a las características estructurales de la Camorra, el modelo de delito asociativo (como hemos mencionado, de derivación fuertemente sociológica y cultural) ${ }^{117}$ crea algunos problemas prácticos, incluso si se compara con una verticalidad atípica de los esquemas de control y poder de la Camorra, por lo cual sus grupos a veces se presentan "difusos" cualitativamente. ${ }^{118}$

La reformulación "infantil" de la Camorra (las llamadas "paranze de criature", "grupos de niños") desde un punto de vista represivo choca con las funciones particulares, normativamente indicadas por la jurisdicción de la justicia juvenil. Si el proceso de menores en Italia está principalmente

115 Por ejemplo, VISCONTI, Costantino: "Strategie di contrasto dell'inquinamento criminale dell'economia: il nodo dei rapporti tra mafie e imprese". En: Rivista italiana di diritto e procedura penale, 2014. Págs. 105 y ss. DALLA CHIESA, Nando: "Mafia e potere oggi”. En: Democrazia e Diritto, № 4, 1983. Págs. 9 y ss.

116 PALIERO, Carlo Enrico Paliero: "Criminalità economica e criminalità organizzata: due paradigmi a confronto". En: Barillaro, Michele (ed.): Criminalità organizzata e sfruttamento delle risorse territoriali. Giuffrè, Milano, 2004. Págs. 141 y ss.

117 Sin embargo, recuerde que esta predicción, que ejemplifica la estrechez de los medios y propósitos perseguidos, así como la posible colusión con el poder político, hace justicia a la perspectiva romántica de las mafias como una sociedad separada y "honrada". El trabajo de desmantelar la visión endulzada y distorsionada de la historia y el carácter de las mafias se debe fuertemente al pensamiento de Leonardo Sciascia.

118 La importancia de la presencia de líderes y promotores, sin embargo, no necesariamente desaparece (nos referimos a la figura del mismo Emanuele Sibillo, el artífice de un tipo particular de grupos camorraciales de jóvenes, definido por la sentencia antes mencionada ex procedimiento $\mathrm{N}^{\circ} 3297 / 15$ GIP el creador más lúcido de este proyecto "adolescente-camorrístico": «dotado de inteligencia y un verdadero carisma, que murió en una emboscada a la edad de 19 años, después de una corta y muy intensa vida. Él es hoy el eterno héroe de los callejones y calles del centro de la ciudad, venerado casi como San Gennaro, en el altar que la familia construyó en su memoria, en el vestíbulo del edificio donde vivía)» (nuestra traducción). 
orientado, con razón, hacia la recuperación del acusado, ${ }^{119}$ un menor que está siendo procesado en un período intermedio de su "educación criminal" (ya que en Nápoles muchos casos de desviación infantil e juvenil, incluso temporales o fisiológicos, abren camino para la Camorra) ${ }^{120}$ posiblemente podría recibir un tratamiento penal demasiado blando y no del todo útil, especialmente si falta la acción oportuna, continua y profunda de los servicios sociales. ${ }^{121}$ La presencia de presidio en forma dura (ideada para minar las fuerzas de la mafia en las cárceles y neutralizar su poder exterior, separando claramente los encarcelados ex art. 41 bis sistema penitenciario del resto de la sociedad) excluye - comprensiblemente - menores (aunque se ha aplicado a adultos jóvenes, considerados muy temibles y promotores

119 Amplius, PENNISI, Angelo (ed.): La giustizia penale minorile. Formazione, devianza, diritto e processo. Giuffrè, Milán, 2012.

120 SALES, Isaia, "Minorenni estorsori della camorra, la «riserva dei boss»". En: https://www.ilmattino.it/napoli/cronaca/minorenni_estorsori_camorra_commento_isaia_ sales-4191648.html. Ver también DE ARCANGELIS, Irene, "La relazione della Dia: 'Minori usati dai clan come esercito di riserva"". En: la Repubblica, edición napolitana, de 14 de febrero de 2019.

121 Los datos presentes al respecto parecen corroborar esta lectura. De hecho, al leer la tabla - presente en el "Documento sui dati statistici dei servizi della Giustizia minorile", del DIPARTIMENTO GIUSTIZIA MINORILE E DI COMUNITÀ, UFFICIO I DEL CAPO DIPARTIMENTO, SEZIONE STATISTICA (DEPARTAMENTO DE JUSTICIA JUVENIL Y COMUNITARIA, OFICINA I DEL DEPARTAMENTO PRINCIPAL, SECCIÓN ESTADÍSTICA: "Documento sobre datos estadísticos de servicios de justicia juvenil"), en https://giustizia.it/resources/cms/documents/quindicinale_15.10.2017_nuovo.pdf. Pág. 7 -, relacionada con menores y adultos jóvenes, a cargo de las oficinas de servicio social para menores, según el lugar y el período donde se hicieron cargo (para el año 2017, hasta el 15 de octubre), realizando una comparación de los datos de las intervenciones implementadas con respecto a las oficinas competentes, donde las cifras relativas a la capital de Campania parecen comparativamente atestiguar una imagen de acciones insuficientes en comparación con lo que se desplegó en otras ciudades italianas, considerando el número de habitantes y, más aún, el alcance de la angustia juvenil presente en Nápoles.

Una situación socioinstitucional problemática, debido a una insuficiencia en términos de represión y prevención, surge de las declaraciones del jefe de la Fiscalía para menores en el distrito del Tribunal de Apelaciones de Nápoles. En este sentido, CERVASIO, Stella: "Maria De Luzenberger: «Senza mezzi efficaci contro i baby criminali»". En: http:// napoli.repubblica.it/cronaca/2017/12/21/news/maria_de_luzenberger_senza_mezzi_efficaci_ contro_i_baby_criminali_-184740945/. A este respecto, también, DI FIORE Gigi: "Mafiosi, stretta sulla patria potestà da Napoli: «Via i figli ai boss»”. En: https://www.ilmattino.it/napoli/ cronaca/mafiosi_stretta_sulla_patria_potesta_via_i_figli_ai_boss-3961595.html y DEL PORTO, Dario: "Minori, le toghe al Csm: «C'è un'escalation di reati»". En: la Repubblica del 11 de septiembre de 2018. 
de estrategias criminales sangrientas, según el Departamento del Distrito Anti-Mafia de Nápoles). ${ }^{122}$

Incidentalmente, debe ser recordado que, como el delito de conspiración mafiosa ${ }^{123}$ ha sido tachado de "anti-garantista" ${ }^{24}$ (igual que la circunstancia agravante de "ambientación mafiosa"), ${ }^{125}$ este modo de ejecución de la sentencia en la cárcel ha sido criticado, a nivel nacional e internacional, por un cierto "anti-humanismo". ${ }^{126}$ De hecho, sin duda, parece ser una

122 DIREZIONE NAZIONALE ANTIMAFIA: "Relazione annuale sulle attività svolte dal Procuratore nazionale antimafia e dalla Direzione nazionale antimafia, nonché sulle dinamiche e le strategie della criminalità organizzata di tipo mafioso nel periodo compreso tra il $1^{\circ}$ luglio 2013 e il 30 giugno 2014" (DIRECCIÓN NACIONAL ANTIMAFIA: "Informe anual sobre las actividades desarrolladas por el Fiscal Nacional Antimafia y la Dirección Nacional Antimafia, así como sobre la dinámica y estrategias de la delincuencia organizada de tipo mafioso en el período comprendido entre el 1 de julio de 2013 y el 30 de junio de 2014"). En: https://www.camera.it/temiap/2015/03/04/OCD177-1033.pdf. Pág. 600.

123 Esto va a sancionar la formación de asociaciones delictivas de tipo mafioso, creadas con fines de "conspiración para cometer delitos", lo cual crea una incertidumbre en la sociedad. Precisamente, el art. 416 bis código penal establece que la asociación es del tipo mafioso cuando los que hacen parte de ella hacen uso de la fuerza y/o intimidación (derivada, precisamente, de ser parte parte de la asociación), para obtener fianzas, condición de sometimiento y omertà (la obligación del silencio tanto utilizada en la historia de la mafia), para cometer crímenes, para adquirir la gestión o control directo o indirecto de actividades económicas, concesiones, autorizaciones, licitaciones públicas y servicios, para obtener beneficios injustos o ventajas para sí mismos o para otros, para prevenir u obstaculizar el libre ejercicio del voto o para obtener votos para sí mismos u otros durante las elecciones electorales. Como notamos, este artículo castiga comportamientos que no están necesariamente dirigidos - directamente - a la comisión de crímenes, y se presentan en realidad como actos instrumentales ("crímenes-medios").

124 Cabe señalar, sin embargo, que la orden de detención europea permite la inclusión de quienes participan en una organización delictiva independientemente de la "doble incriminación”: TURONE, Giuliano: Il delitto di associazione mafiosa. Giuffré, Milán, 2008. Págs. 316 y ss.

125 DELLA RAGIONE, Luca: "L'aggravante della "ambientazione mafiosa" (art. 7 d.1. 13.5.1991, n. 152)". En: Maiello, Vincenzo (ed.): La legislazione penale in materia di criminalità organizzata, misure di prevenzione ed armi. Giappichelli, Turín, 2015. Págs. 72 y ss.

126 Sobre esta cuestión, CALDERONE, Maria Rosaria: "L'articolo 41 bis Ord. pen. e altri regimi particolari di detenzione. Aspetti giuridici e sociologici". En: http:// www.altrodiritto.unifi.it/rivista/2005/calderone/index.htm; FONTANELLI, Elisa: "L'art. 41-bis 1. 354/75 come strumento di lotta contro la mafia". En: https://web.archive.org/ web/20110722040856/http://www.altrodiritto.unifi.it/ricerche/misure/fontanel/index. $\mathrm{htm}$. Este tipo de encarcelamiento, aunque se enmarca como una medida de emergencia temporal, destinada a eliminar la posibilidad de que los jefes de la mafia salgan de prisión, cortando sus contactos con el mundo exterior, se usa de forma permanente; estableciendo un modelo de detención sistemático particularmente aflictivo. En sus críticas: AMNESTY 
herramienta eficaz (al menos, útil por su carácter intimidante), como lo demuestran las demandas "políticas" de las mafias italianas que en los años han constituido una plataforma para su abolición ${ }^{127}$ (guiñando a los diferentes partidos políticos, desde la derecha crítica del aparato judicial de Berlusconi ${ }^{128}$ hasta una cierta izquierda extra-parlamentaria contraria tout court a la prisión como castigo). ${ }^{129} \mathrm{La}$ importancia de este tipo de encarcelamiento, además de ser considerada a nivel psicológico y simbólico social (ir, junto con los instrumentos de agresión del patrimonio de la mafia, a socavar el capital social de las organizaciones) ${ }_{,}^{130}$ también está determinada por el hecho de favorecer los fenómenos de colaboración con la justicia (el llamado "pentitismo", tan temido y opuesto ${ }^{131}$ por los clanes). ${ }^{132}$ Sin embargo, el problema real, no solo relacionado con esta

INTERNATIONAL: “Amnesty International Report 2003 - Italy, 28 May 2003”. En: http:// www.refworld.org/docid/3edb47d8c.html. COMISIÓN DE LIBERTADES Y DERECHOS DE LOS CIUDADANOS, JUSTICIA Y ASUNTOS INTERIORES, PARLAMENTO EUROPEO: "Informe de 24 de febrero de 2004 con una propuesta de recomendación del Parlamento Europeo destinada al Consejo sobre los derechos de los detenidos en la Unión Europea (2003/2188(INI))". En: http://www.europarl.europa.eu/sides/getDoc.do?pubRef=-// EP//TEXT+REPORT+A5-2004-0094+0+DOC+XML+V0//ES.

127 A este respecto, por ejemplo, "L'abrogazione articolo 41 bis". En: https:// it.wikipedia.org/wiki/Trattativa_tra_Stato_italiano_e_Cosa_nostra\#L'abrogazione articolo_41_bis.

128 Véase BELLAVIA, Enrico: "Allo stadio di Palermo striscione anti-41 bis". En: la Repubblica del 23 de diciembre de 2002. La pancarta expuso lo siguiente: «Unidos contra 41 bis. Berlusconi se olvida de Sicilia».

129 Sin embargo, para un comentario detallado de un Presidente del Tribunal de Vigilancia de L'Aquila a una nueva propuesta reciente de la abolición de este método de prisión de "izquierda": LONGO, Laura: "41 bis". En: https://poterealpopolo.org/41bis/.

130 Cabe señalar, en los márgenes, que incluso la captura de fugitivos (no siempre normativamente fácil, debido a las diferencias legislativas a nivel internacional) es simbólicamente importante, además prácticamente, ya que va a aniquilar a los que tienen un pensamiento sistemático superior.

131 La batalla contra estos "informantes", que a menudo convierte a ellos y a sus familiares en posibles víctimas de asesinatos por parte de los grupos camorristas, también se condena simbólicamente a través de mensajes con un fuerte impacto. Por ejemplo: SAUTTO, Dario: "Castellammare, falò dell'Immacolata con messaggio della camorra: «Pentiti bruciati»". En: https://ilmattino.it/napoli/cronaca/castellammare_falo_immacolata messaggio_camorra_pentiti_bruciati-4159601.html.

132 El temor a sufrir el encarcelamiento en esta dura forma es esencial para la colaboración en investigaciones, especialmente para jefes y afiliados acostumbrados a la "buena vida" (como un producto directo de su trayectoria criminal). Para aquellos que no están ajenos al "sacrificio" como consecuencia de la vida de crimen (piensen en aquellos que están acostumbrados a una fuga de los arrestos muy incómoda, por nada "dorada"), este encarcelamiento es mucho menos efectivo para este propósito. Sobre lo problemático de un potencial utilizo incorrecto de la medida, hay que recordar que el Comitato europeo para la 
disposición regulatoria, de una ejecución "efectiva" y socialmente "útil"133 con respecto a los sujetos condenados por delitos relacionados con el crimen organizado también se debe tomar en consideración el peligro de una "victimización" (paradójica o no) de tales presos. ${ }^{134}$

De alguna manera, no podemos dejar de preguntarnos si las reglas de lucha contra la mafia no entran completamente en la lógica de las leyes de emergencia (siguiendo así las líneas trazadas en el pasado por la represión del terrorismo interno) y, por lo tanto, si no tienen que ser examinadas y reconsideradas en relación con el momento histórico vigente.

De hecho, se discute si se puede hablar sobre la existencia de un derecho punitivo ad hoc (y la aplicación de una ley penal "material" que no siempre coincide con la estructurada formalmente), específicamente orientado al contexto con una autonomía muy fuerte frente a esquemas y contenidos comunes. ${ }^{135}$ Por otro lado, se conoce como la legislación de "emergencia"136 (a la que ciertamente se pueden relacionar a ciertas disposiciones en materia de mafias), al referirse tanto a la realidad como a la percepción de los fenómenos, también debido a la necesidad de un tipo simbólico ${ }^{137}$ que pueda dar la sensación, si no es de una solución,

prevención de la tortura y penas o tratos inhumanos o humillantes ha expresado dudas en relación con el utilizo instrumental de tal régimen de detención especial, donde el intento sea precisamente aquello especifico de inducir a los detenidos a la colaboración con el poder judicial.

133 Correlativamente, para una discusión sobre la posible aplicación de una justicia "reparadora" en la lucha contra el crimen organizado de carácter económico, GALAIN PALERMO, Pablo, ROMERO SÁNCHEZ, Angélica: "Criminalidad organizada y reparación. ¿Puede la reparación ser un arma político-criminal efectiva en la lucha contra la criminalidad organizada?”. En: Derecho Penal y Criminología, vol. 22, No 73, 2001. Págs. 45 y ss.

134 MAPELLI CAFFARENA, Borja: "Problemas de la ejecución penal fruente a la criminalidad organizada". En: Gutiérrez-Alviz Conradi, Faustino (ed.): La criminalidad organizada ante la justicia. Universidad de Sevilla. Secretariado De Publicaciones, Sevilla, 1996. Págs. 53 y ss.

135 Ver SÁNCHEZ GARCÍA DE PAZ, Isabel: La criminalidad organizada: aspectos penales, procesales, administrativos y policiales. Dykinson, Madrid, 2005, especialmente el capítulo "Derecho penal material: ¿un derecho penal ad hoc contra el crimen organizado?". Págs. 103 y ss.

136 BRICOLA, Franco: "Premessa al commento della legge 13 settembre 1992, n. 646”. En: La legislazione penale, 1983. Pág. 238.

137 MOCCIA, Sergio: "Prospettive non emergenziale di controllo dei fatti di criminalità organizata". En: Moccia, Sergio (ed.): Criminalità organizzata e risposte ordinamentali, ob. cit. Págs. 151 y ss. 
al menos de una reducción inmediata del problema, ${ }^{138}$ tiende a originar previsiones que están extremadamente ancladas a los marcos tomados en consideración. ${ }^{139}$ Ante la magnitud del problema del crimen organizado, en cualquier caso, no es sorprendente el esfuerzo "extraordinario" realizado por el sistema penal (en cierto modo, después de un largo sueño) ${ }^{140}$ para "deconstruir" 141 y hacer frente a un complejo fenómeno criminal que ha sido considerado socialmente calificable como una amenaza real para la seguridad del Estado ${ }^{142}$ y un ataque radical al orden socio-jurídico. ${ }^{143}$ Así pues, el derecho penal se caracteriza de varias maneras como un derecho que

138 ZAFFARONI, Eugenio Raúl: "La creciente legislación penal y los discursos de emergencia”. En: AA. VV.: Teorías actuales en el derecho penal. Ad-Hoc, Buenos Aires, 1998. Pág. 613.

139 DELL'OSSO, Alain Maria: 'I 'limiti' del reato di associazione di tipo mafioso di fronte alle 'mafie in trasferta"'. En: Rivista di Studi e Ricerche sulla criminalità organizzata, vol. 2, No 4, 2016. Pág. 33.

$140 \quad$ Véase MILITELLO, Vincenzo: "Lucha contra la criminalidad organizada de tipo mafioso y el sistema penal italiano". En: González-Cuéllar Serrano, Nicolás, Sanz Hermida, Ágata María, Ortiz Pradillo, Juan Carlos (eds.): ob. cit. Págs. 120 y ss.

141 Ver ZAVALETA LOPEZ, Luis Alberto: "El efecto desestabilizador como fundamento de la política criminal contra la criminalidad organizada". En: https://legis.pe/ efecto-desestabilizador-politica-criminal-criminalidad-organizada/.

142 ZÚÑIGA RODRÍGUEZ, Laura, BALLESTEROS SÁNCHEZ, Julio (eds.): La criminalidad organizada transnacional: una amenaza a la seguridad de los Estados democráticos. Ediciones Universidad de Salamanca, Valencia, 2017 y LOPEZ SANCHEZ, José: "La Delincuencia organizada como amenaza estratégica". En: González Rus, Juan José: La criminalidad organizada. Tirant Lo Blanch, Valencia, 2013. Págs. 329 y ss. Por nuevas formas que pueden tomar tal amenaza, por modalidad sin precedentes en la acción del crimen organizado, FERNÁNDEZ HERNÁNDEZ, Antonio, CUERDA ARNAU, María Luisa: Nuevas amenazas a la seguridad nacional. Terrorismo, criminalidad organizada y tecnologías de la información y la comunicación. Tirant Lo Blanch, Valencia, 2013. Sobre la cuestión, ver también DÓMINE, María Cecilia: "Criminalidad económica y terrorismo.". En: Revista de Derecho. Publicación de la Facultad de Derecho de la Universidad Católica de Uruguay, $\mathrm{N}^{\mathrm{o}} 1,2006$. Págs. 83 y ss.

143 Sobre la desestabilización del orden público, LÓPEZ MUÑOZ, Julián: "El Orden público bajo la amenaza de la criminalidad organizada". En: Revista de Derecho de la UNED, $\mathrm{N}^{\mathrm{o}} 13$, 2013. Págs. 233 y ss. 
se enfoca en el "enemigo", ${ }^{144}$ un derecho "de lucha"145 y "de excepción", ${ }^{146}$ que necesariamente proporciona respuestas "excepcionales" e inhabituales a contingencias. Sin embargo, además de tener que debatir la verdadera naturaleza de esta "excepcionalidad" (subjetiva, temporal, objetiva, etc.), este marco regulatorio indudablemente plantea ciertos problemas de legitimidad ${ }^{147}$ (así como un potencial vulnus al respeto de los derechos humanos). ${ }^{148}$ Evidentemente, estas preguntas también interesan de forma determinante algunas disposiciones específicas del derecho penitenciario, ${ }^{149}$

144 CANCIO MELIÁ, Manuel, GÓMEZ-JARA DÍEZ, Carlos (eds.): Derecho penal del enemigo. El discurso penal de la exclusión. Edisofer, Madrid-Buenos Aires-Montevideo, 2006.

145 DONINI, Massimo: "Derecho penal de lucha. Lo que el debate sobre el Derecho penal del enemigo no debe limitarse a exorcizar". En: Cancio Meliá, Manuel, Pozuelo Pérez, Laura (eds.): Política criminal en vanguardia: Inmigración clandestina, terrorismo, criminalidad organizada. Civitas, Navarra, 2008. Págs. 29 y ss.

146 PRIETO, Evaristo: "Excepción y normalidad como categorías de lo político". En: Cancio Meliá, Manuel, Pozuelo Pérez, Laura (eds.): ob. cit. Págs. 77 y ss.

147 SÁNCHEZ GARCÍA DE PAZ, Isabel: "Problemas de legitimidad de una respuesta excepcional frente a las organizaciones criminales". En: Cancio Meliá, Manuel, Pozuelo Pérez, Laura (eds.), ob. cit. Págs. 451 y ss. Además, la necesidad de atacar formas específicas de ser de la delincuencia globalizada parece haber llevado también a una erosión de los principios fundamentales. En cuanto, por ejemplo, a el debilitamiento del nemo tenetur se detergere, así como los pilares de precisión de la norma penal, CASTALDO, Andrea: "Una introducción al problema". En: Yacobucci, Guillermo J.: El crimen organizado. Desafios y perspectivas en el marco de la globalización. Ábaco de Rodolfo Depalma, Buenos Aires, 2005. Págs. 277 y ss.

148 En el tema, también PÉREZ LUÑO, Antonio Enrique: La universalidad de los derechos humanos y el Estado constitucional. Universidad Externado de Colombia, Bogotá, 2002. Pág. 62.

149 Considere la aplicación del llamado "impedimento" de cadena perpetua de conformidad con el art. 4 bis, párrafo 1, del sistema penitenciario, que establece la imposibilidad de acceder a cualquier medida alternativa a la prisión y cualquier beneficio penitenciario, a menos que coopere con la justicia. Esta disposición ha sido recientemente objeto de censuras en sede judicial tanto europea come nacional. En concreto, después de la decisión de 2019, para el Tribunal Europeo de Derechos Humanos, la disposición es contraria al artículo 3 de la Convención sobre Derechos Humanos, que prohíbe el "trato inhumano y degradante", en la medida en que la "no cooperación" no implica necesariamente que la persona condenada no se haya arrepentida de sus actos o que aún está en contacto con grupos criminales o, que por eso, dicha persona constituya un peligro para la sociedad (la elección de colaborar con la justicia puede no ser totalmente libre, sino depender de otros factores, como el miedo a poner en peligro la propia vida o la de los seres queridos; del mismo modo, no es necesariamente el caso de que la colaboración siempre implique arrepentimiento y el fin de las relaciones con otros delincuentes). El Tribunal Constitucional, en el mismo año, declaró la ilegitimidad constitucional del artículo antes mencionado, en la parte en que no permite, para aquellos que hayan sido condenados por crímenes de la mafia, la concesión de permisos de salida adjudicación en ausencia de colaboración con la justicia, incluso si se han adquirido 
un tema que ya se trató parcialmente. Por último, pero no menos importante, la internacionalización (necesaria) de la ley punitiva introduce, de manera centrífuga, un pluralismo horizontal y vertical de fuentes normativas (cada una con su propio universo cultural) tradicionalmente ajenas al sistema legal de cada Estado, que puede fuertemente ir contra la garantía constitucional de la legalidad. ${ }^{150}$

Entonces, en conclusión, se puede decir que la reflexión sobre la realidad camorrística solo puede ser, por supuesto, también una reflexión sobre la sociedad, sobre la economía y sobre el derecho, en su complejidad $\mathrm{y}$ en su progreso.

\section{Bibliografía.}

AA. VV.: Mafia Capitale. En: Meridiana. Rivista di Studi Storici e Sociali, $\mathrm{N}^{\circ} 87,2016$.

ALLUM, Felia: The Invisible Camorra. Neapolitan Crime Families across Europe. Cornell University Press, Ithaca- Londres, 2016.

AMNESTY INTERNATIONAL: “Amnesty International Report 2003 Italy, 28 May 2003”. En: http://www.refworld.org/docid/3edb47d8c.html.

ANARTE BORRALLO, Enrique: "Conjeturas sobre la criminalidad organizada". En: Ferré Olivé, Juan Carlos, Anarte Borrallo, Enrique (eds.): Delincuencia organizada. Aspectos penales, procesales y criminológicos. Universidad de Huelva, Huelva, 1999.

BARATTA, Alessandro: "Mafia: rapporti tra modelli criminologici e scelte di politica criminale". En: Moccia, Sergio (ed.): Criminalità organizzata e risposte ordinamentali. Tra efficienza e garanzia. Esi, Nápoles, 1999.

elementos que excluyen tanto la actualidad de la participación en la asociación delictiva como, en general, el peligro de restablecer vínculos con el crimen organizado (siempre que el condenado haya dado prueba completa de su participación en el camino reeducativo).

150 Sobre las características de este proceso, que también recordaría la Edad Media del Derecho, DONINI, Massimo: "Escenarios del Derecho Penal en Europa a principios del siglo XXI". En: Mir Puig, Santiago, Corcoy Bidasolo, Mirentxu, Gómez Martín, Víctor Gómez (eds.): La politica criminal en Europa. Atelier, Barcelona, 2004. Pág. 44. 
BARBAGALLO, Francesco: Storia della camorra. Laterza, Roma-Bari, 2010.

BEHAN, Tom: See Naples and Die. The Camorra Organized Crime, Tauris, Londres, 2002.

BELLAVIA, Enrico: "Allo stadio di Palermo striscione anti-41 bis". En: la Repubblica del 23 de diciembre de 2002.

BENIGNO, Francesco: "La questione delle origini: mafia, camorra e storia d'Italia". En: Meridiana. Rivista di Studi Storici e Sociali, N. . 87, 2016.

BIANCONI, Giovanni: "«Non serve gente che spara, meglio chi sa usare la Rete». Gli affari dei clan con i giochi”. En: Corriere della Sera de 15 de noviembre de 2018.

BLANCO CORDERO, Isidoro: "Principales instrumentos internacionales (de Naciones Unidas y la Unión Europea) relativos al crimen organizado: la definición de la participación en una organización criminal y los problemas de la aplicación de la Ley Penal en el espacio". En: AA. VV.: Criminalidad organizada. Reunión de la sección nacional española preparatoria del XVI Congreso de la AIDP en Budapest. Gabinete del Rector de la Universidad de Castilla-La Mancha, Ciudad Real, 1999.

BRANCACCIO, Luciano: "Mafia Capitale: associazione mafiosa e fazione politica”. En: Meridiana. Rivista di Studi Storici e Sociali, N. ${ }^{\circ}$ 87, 2016.

BRANCACCIO, Luciano: I clan di camorra. Genesi e storia. Donzelli, Roma, 2017.

BRICOLA, Franco: "Premessa al commento della legge 13 settembre 1992, n. 646". En: La legislazione penale, 1983. MOCCIA, Sergio: "Prospettive non emergenziale di controllo dei fatti di criminalità organizata". En: Moccia, Sergio (ed.): Criminalità organizzata e risposte ordinamentali. Tra efficienza e garanzia, Esi, Nápoles, 1999.

CACIAGLI, Mario: Clientelismo, corrupción y criminalidad organizada. Evidencias empíricas y propuestas teóricas a partir de los casos italianos. Centro de Estudios Constitucionales, Madrid, 1996.

CALDERONE, Maria Rosaria: "L'articolo 41 bis Ord. pen. e altri regimi particolari di detenzione. Aspetti giuridici e sociologici". En: http://www. altrodiritto.unifi.it/rivista/2005/calderone/index.htm. 
CANCIO MELIÁ, Manuel, GÓMEZ-JARA DÍEZ, Carlos (eds.): Derecho penal del enemigo. El discurso penal de la exclusión. Edisofer, MadridBuenos Aires-Montevideo, 2006.

CARMONA, Angelo: Premesse a un corso di diritto penale dell'economia. Mercato, regole e controllo penale nella postmodernità. Cedam, Padua, 2002.

CASELLI, Carlo: "Los instrumentos internacionales en la lucha contra el crimen organizado". En: Cámara de Landa, Enrique, Morabito, Stefano (eds.): Mafia, 'Ndrangheta, Camorra. En los entresijos del poder paralelo. Universidad de Valladolid, Valladolid, 2005.

CASTALDO, Andrea: "Una introducción al problema". En: Yacobucci, Guillermo J.: El crimen organizado. Desafios y perspectivas en el marco de la globalización. Ábaco de Rodolfo Depalma, Buenos Aires, 2005

CAVALIERE, Flavia: "Gomorrah". En: European Journal of English Studies, 2010, N 14:2.

CAVALIERO, Antonio: "Il concorso eventuale nel reato associativo. Le ipotesi delle associazioni per delinquere di tipo mafioso". Esi, Nápoles, 2003.

CENTORRINO, Mario: "Criminalidad Transnacional y Procesos de Globalización”. En: Cámara de Landa, Enrique, Morabito, Stefano (eds.): Mafia, 'Ndrangheta, Camorra. En los entresijos del poder paralelo. Universidad de Valladolid, Valladolid, 2005.

CERVASIO, Stella: "Maria De Luzenberger: «Senza mezzi efficaci contro i baby criminali»»". En: http://napoli.repubblica.it/cronaca/2017/12/21/ news/maria_de_luzenberger_senza_mezzi_efficaci_contro_i_baby_ criminali_-184740945/.

CESANO, José Daniel: "Criminalidad Económica e Internacionalización del Derecho Penal: experiencias en la Unión Europea y en el Mercosur". En: Revista Internacional Derecho Penal Contemporáneo, No $.24,2008$.

COLLETTI, Alessandro: Il welfare e il suo doppio. Percorsi etnografici nelle camorre del casertano. Ledizioni, Milano, 2016.

COMISIÓN DE LIBERTADES Y DERECHOS DE LOS CIUDADANOS, JUSTICIA Y ASUNTOS INTERIORES, PARLAMENTO EUROPEO: "Informe de 24 de febrero de 2004 con una propuesta de recomendación 
del Parlamento Europeo destinada al Consejo sobre los derechos de los detenidos en la Unión Europea (2003/2188(INI))". En: http://www.europarl. europa.eu/sides/getDoc.do?pubRef=-//EP//TEXT+REPORT+A5-20040094+0+DOC+XML+V0//ES.

COMMISSIONE PARLAMENTARE ANTIMAFIA: Camorra e politica. Laterza, Roma-Bari, 1994.

CORNEJO Abel: Asociación ilícita. Ad-hoc, Buenos Aires, 1992.

CORTE DEI CONTI, SEZIONE CENTRALE DI CONTROLLO SULLA GESTIONE DELLE AMMINISTRAZIONI DELLO STATO: "L'amministrazione dei beni sequestrati e confiscati alla criminalità organizzata e l'attività dell'agenzia nazionale (ANBSC). Deliberazione 23 giugno 2016, n. 5/2016/G”. En: http://www.corteconti.it/export/ sites/portalecdc/_documenti/controllo/sez_centrale_controllo_amm_ stato/2016/delibera_5_2016_g.pdf.

CURBET, Jaume: La glocalización de la (in)seguridad. Plural, La Paz, 2006.

D'ADDOSIO, Carlo: Il duello dei camorristi. Editore Lello Pierro, Nápoles, 1893.

D'ALFONSO, Stefano: "Professioni liberali e area grigia. Per un'antimafia degli ordini professionali". En: Brancaccio, Luciano, Castellano, Carolina (eds.): Affari di camorra. Famiglie, imprenditori e gruppi criminali. Donzelli, Roma, 2015.

DAGNES, Joselle, DONATIELLO, Davide, SCIARRONE, Rocco, STORTI, Luca: "Le mafie italiane all'estero: un'agenda di ricerca". En: Meridiana. Rivista di Studi Storici e Sociali, N. ${ }^{\circ}$ 87, 2016.

DALLA CHIESA, Nando: "A proposito di Mafia Capitale. Alcuni problemi teorici”. En: Rivista di Studi e Ricerche sulla criminalità organizzata, $\mathrm{N}^{\circ}$ $2,2015$.

DALLA CHIESA, Nando: "Mafia e potere oggi". En: Democrazia e Diritto, N 4, 1983.

DE FRANCESCO, Giovannangelo: "Societas sceleris. Tecniche repressive delle associazioni criminali". En: Rivista italiana di diritto e procedura penale, 1992. 
DE ARCANGELIS, Irene: "La camorra copia la fiction: c'è "Sangue blu" che rivuole Forcella". En: la Repubblica, edicion napolitana, de 30 de enero de 2019.

DE ARCANGELIS, Irene, "La relazione della Dia: 'Minori usati dai clan come esercito di riserva"'. En: la Repubblica, edicion napolitana, de 14 de febrero de 2019.

DE JACO, Aldo: Napoli monarchica, milionaria, repubblicana. Newton Compton, Roma, 1982.

DEL PORTO Dario: “Minori, le toghe al Csm: «C'è un'escalation di reati»". En: la Repubblica del 11 de septiembre de 2018.

DELL'ARTI, Giorgio: "Biografia di Augusto La Torre". En: http:// cinquantamila.corriere.it/storyTellerThread.php?threadId=LA\%20 TORRE\%20Augusto.

DELL'OSSO, Alain Maria: "I 'limiti' del reato di associazione di tipo mafioso di fronte alle "mafie in trasferta"'. En: Rivista di Studi e Ricerche sulla criminalità organizzata, vol. 2, No 4, 2016.

DELLA RAGIONE, Luca: "L'aggravante della "ambientazione mafiosa" (art. 7 d.1. 13.5.1991, n. 152)". En: Maiello, Vincenzo (ed.): La legislazione penale in materia di criminalità organizzata, misure di prevenzione ed armi. Giappichelli, Turín, 2015.

DI FIORE, Gigi: "La banda milanese infatuata di Gomorra: per fare le rapine si ispirava alla fiction". http://www.ilmattino.it/napoli/cronaca/la banda_milanese_infatuata_di_gomorra2499627.html.

DI FIORE, Gigi: "Mafiosi, stretta sulla patria potestà da Napoli: «Via i figli ai boss»". En: https://www.ilmattino.it/napoli/cronaca/mafiosi_stretta sulla_patria_potesta_via_i_figli_ai_boss-3961595.html.

DI MARCO, Emiliano: "I collegamenti tra camorra e jihad islamica. Napoli crocevia dei traffici e base logistica". En: https://www.agoravox. it/I-collegamenti-tra-camorra-e-jihad.html.

DI MEO, Simone: "Chi sono i cinque camorristi nel mirino dell'intelligence Usa”. En: Il Sole 24 ore de 6 de agosto de 2013.

DIPARTIMENTO GIUSTIZIA MINORILE E DI COMUNITÀ, UFFICIO I DEL CAPO DIPARTIMENTO, SEZIONE STATISTICA: "Documento 
sui dati statistici dei servizi della Giustizia minorile". En: https://giustizia. it/resources/cms/documents/quindicinale_15.10.2017_nuovo.pdf.

DIREZIONE NAZIONALE ANTIMAFIA: "Relazione annuale sulle attività svolte dal Procuratore nazionale antimafia e dalla Direzione nazionale antimafia, nonché sulle dinamiche e le strategie della criminalità organizzata di tipo mafioso nel periodo compreso tra il $1^{\circ}$ luglio 2013 e il 30 giugno 2014". En: https://www.camera.it/temiap/2015/03/04/OCD1771033.pdf.

DÓMINE, María Cecilia: "Criminalidad económica y terrorismo.". En: Revista de Derecho. Publicación de la Facultad de Derecho de la Universidad Católica de Uruguay, № 1, 2006.

DONINI, Massimo: "Derecho penal de lucha. Lo que el debate sobre el Derecho penal del enemigo no debe limitarse a exorcizar". En: Cancio Meliá, Manuel, Pozuelo Pérez, Laura (eds.): Política criminal en vanguardia: Inmigración clandestina, terrorismo, criminalidad organizada. Civitas, Navarra, 2008.

DONINI, Massimo: "Escenarios del Derecho Penal en Europa a principios del siglo XXI". En: Mir Puig, Santiago, Corcoy Bidasolo, Mirentxu, Gómez Martín, Víctor (eds.): La política criminal en Europa, Atelier, Barcelona, 2004.

DURRIEU FIGUEROA, Roberto: La ganancia económica del delito. Lavado de dinero, decomiso y financiamiento del crimen organizado y del terrorismo. Marcial Pons Argentina, Buenos Aires, 2017.

EURISPES: Rapporto Italia 2017, Minerva, Argelato (BO), 2017.

FARANO, Adriano: "Roberto Saviano: «La Spagna? Per la Camorra è Costa nostra»". En: https://cafebabel.com/it/article/roberto-saviano-la-spagnaper-la-camorra-e-costa-nostra-5ae004fcf723b35a145dc889/. SAINI, Valentina: "Catamorra, come le mafie hanno colonizzato la Catalogna". En: https://www.glistatigenerali.com/criminalita_napoli/catamorra-comele-mafie-hanno-colonizzato-la-catalogna/.

FERNÁNDEZ HERNÁNDEZ, Antonio, CUERDA ARNAU, María Luisa: Nuevas amenazas a la seguridad naciona. Terrorismo, criminalidad organizada y tecnologías de la información y la comunicaciónen. Tirant Lo Blanch, Valencia, 2013. 
FIANDACA, Giovanni: "Il concorso 'esterno' tra sociologia e diritto penale”. En: Foro italiano, 2010, Vol. V.

FIANDACA, Giovanni: "Il concorso esterno tra guerre di religione e laicità giuridica”. En: Diritto penale contemporanteo, 2012, Págs. 253 y ss., en https://www.penalecontemporaneo.it/upload/1331919165Fiandaca $\% 20$ su\%20processo\%20DellUtri.pdf.

FISHER, Peter A.: "È sbagliato demonizzare". En: Internazionale del 10/16 de noviembre de 2017, $\mathrm{N}^{\circ} 1230$.

FONTANELLI, Elisa: "L'art. 41-bis 1. 354/75 come strumento di lotta contro la mafia". En: https://web.archive.org/web/20110722040856/http:// www.altrodiritto.unifi.it/ricerche/misure/fontanel/index.htm.

FORNARI,Luigi: "Ilmetodomafioso: dall'effettività deirequisitial 'pericolo d'intimidazione' derivante da un contesto criminale? Di 'mafia' in 'mafia', fino a 'Mafia Capitale"'. En: Diritto penale contemporaneo, 2016, en https:// www.penalecontemporaneo.it/upload/1465420783FORNARI_2016a.pdf.

FORNARI, Luigi: "Il principio di tassatività alla prova della "lotta" alla mafia: contiguità e metodo mafioso". En: Cocco, Giovanni (ed): Trattato breve di diritto penale. Temi contemporanei. Per un manifesto del neoilluminismo penale. Cedam, Padua, 2016.

FRANCESCUTTI PÉREZ, Pablo: La pantalla profética: cuando las ficciones se convierten en realidad. Cátedra, Madrid, 2004.

G.I.P. TRIBUNALE DI NAPOLI: "Sentenza processo penale $\mathrm{N}^{\circ}$ 3297/15 G.I.P.”.

GALAIN PALERMO, Pablo, ROMERO SÁNCHEZ, Angélica: "Criminalidad organizada y reparación. ¿Puede la reparación ser un arma político-criminal efectiva en la lucha contra la criminalidad organizada?". En: Derecho Penal y Criminología, vol. 22, No 73, 2001.

GARAVINI, Laura: "Mafia? Nein danke! - La più grande ribellione al pizzo fuori dall'Italia". En: https://mafianeindanke.de/mnd-storia/.

GARGANI: "Verso una 'democrazia giudiziaria'? I poteri normativi del giudice tra principio di legalità e diritto europeo". En: Criminalia. 2011.

GAYRAUD, Jean-François: El G9 de las mafias en el mundo. Geopolítica del crimen organizado. Tendencias, España, 2007. 
GIMÉNEZ-SALINAS FRAMIS, Andrea: "La delincuencia organizada en Europa: extensión, factores facilitadores y rasgos principales". En: CENTRO SUPERIOR DE ESTUDIOS DE LA DEFENSA NACIONAL: La lucha contra el crimen organizado en la Unión Europea, Ministerio de Defensa, España, 2012

GÓMEZ DE LIAÑO FONSECA HERRERO, Marta: Criminalidad organizada y medios extraordinarios de investigación. Colex, Madrid, 2004.

KAZYRYTSKI, Leanid: “Criminalidad organizada y bandas juveniles: reflexiones criminológicas sobre la naturaleza de ambos fenómenos". En: Revista de Derecho Penal y Criminología, N 8, 2012.

LAGAZZI, Marco, MARUGO, Maria Ida: "La ricerca in tema di criminalità organizzata: approcci interpretativi e problematiche metodologiche". En: Bandini, Tullio, Lagazzi, Marco, Marugo, Maria Ida (eds.): La criminalità organizzata. Moderne metodologie di ricerca e nuove ipotesi esplicative. Giuffrè, Milano, 1993.

LAMBERTI, Amato: La camorra. Evoluzione e struttura della criminalità organizzata in Campania. Boccia Editore, Salerno, 1992.

LEWIS, Norman: Naples '44. William Collins, Londres, 1978.

LOMBARDI SATRIANI, Luigi M.: "En torno a la mafia". En: Cámara de Landa, Enrique, Morabito, Stefano (eds.): Mafia, 'Ndrangheta, Camorra. En los entresijos del poder paralelo. Universidad de Valladolid, Valladolid, 2005.

LONGO, Laura: “41 bis”. En: https://poterealpopolo.org/41bis/.

LÓPEZ BARJA DE QUIROGA, Jacobo: "Posición de la Unión Europea sobre el crimen organizado". En: Granados Perez, Carlos (ed.): La criminalidad organizada. Aspectos sustantivos, procesales y orgánicos. Consejo General del Poder Judicial, Madrid, 2001.

LÓPEZ MUÑOZ, Julián: "El Orden público bajo la amenaza de la criminalidad organizada". En: Revista de Derecho de la UNED, $\mathrm{N}^{\circ} 13$, 2013.

LÓPEZ MUÑOZ, Julián: Criminalidad organizada. Aspectos jurídicos y criminológicos. Dykinson, Madrid, 2015. 
LÓPEZ POZOS, Cecilia: "El teatro terrorífico: estrategia de acoso del crimen organizado". En: Visioni LatinoAmericane, 2018, № 18.

LOPEZ SANCHEZ, José: "La Delincuencia organizada como amenaza estratégica”. En: González Rus, Juan José: La criminalidad organizada. Tirant Lo Blanch, Valencia, 2013.

LUPO, Salvatore: "Criminalità organizzata". En: http://www.treccani.it/ enciclopedia/criminalita-organizzata/.

MAIELLO, Vincenzo: Il concorso esterno tra indeterminatezza legislativa e tipizzazione giurisprudenziale. Giappichelli, Turín, 2014.

MANNA, Adelmo: "L'ammissibilità di un c.d. concorso "esterno" nei reati associativi, tra esigenze di politica criminale e principio di legalità". En: Rivista italiana di diritto e procedura penale, 1994.

MAPELLI CAFFARENA, Borja: "Problemas de la ejecución penal fruente a la criminalidad organizada". En: Gutiérrez-Alviz Conradi, Faustino (ed.): La criminalidad organizada ante la justicia. Universidad de Sevilla. Secretariado De Publicaciones, Sevilla, 1996.

MARMO, Marcella: Il coltello e il mercato. La camorra prima e dopo l'Unità d'Italia. L'ancora del Mediterraneo, Nápoles-Roma, 2011.

MARTONE, Vittorio: "La camorra come stakeholder nella governance del territorio". En: Meridiana. Rivista di Studi Storici e Sociali, N 73, 2012.

MARVASI, Roberto: La tragedia Cuocolo: governo, polizia e camorra. Edizioni di Scintilla, Nápoles, 1907.

MEDINA ARIZA, Juan José: "Una introducción al estudio criminológico del crimen organizado". En: Ferré Olivé, Juan Carlos, Anarte Borrallo, Enrique (eds.): Delincuencia organizada. Aspectos penales, procesales y criminológicos. Universidad de Huelva, Huelva, 1999.

MEDINA ARIZA, Juan José: "Una introducción al estudio criminológico del crimen organizado". En: Ferré Olivé, Juan Carlos, Anarte Borrallo, Enrique (eds.): Delincuencia organizada. Aspectos penales, procesales y criminológicos. Universidad de Huelva, Huelva, 1999.

MEDINA, Juanjo: "Consideraciones criminológicas sobre las bandas juveniles”. En: Revista de Derecho Penal y Criminología, № 3, 2010. 
MILITELLO, Vincenzo: "Lucha contra la criminalidad organizada de tipo mafioso y el sistema penal italiano". En: González-Cuéllar Serrano, Nicolás, Sanz Hermida, Ágata María, Ortiz Pradillo, Juan Carlos (eds.): Problemas actuales de la justicia penal. Colex, Madrid, 2013. MONNIER Marco: La camorra: mystères de Naples. Michel Lévy frères, París, 1863.

MOTTOLA, Giorgio: Camorra nostra. Nascita di una S.p.a. del crimine. Sperling \& Kupfer, Milano, 2017.

NACCARI, Tommaso: "L'influenza di Gomorra sul rap francese". En: https://noisey.vice.com/it/article/rkwxda/gomorra-rap-francese.

NOVI, Errico: “«L'Agenzia nazionale incapace di gestire le aziende sequestrate»". En: Il dubbio de 11 de abril de 2018.

PAGANI, Steve: "Camorra clans in control behind Naples facades". En: Reuters del 26 del enero de 1999.

PALAZZO, Francesco: "Legalità penale: considerazioni su trasformazione e complessità di un principio 'fondamentale"'. En: Quaderni fiorentini per la storia del pensiero giuridico moderno, vol. XXXVI, 2007.

PALAZZO, Francesco: "La mafia hoy: evolución criminológica y legislativa". En: Ferré Olivé, Juan Carlos, Anarte Borrallo, Enrique (eds.): Delincuencia organizada. Aspectos penales, procesales y criminológicos. Universidad de Huelva, Huelva, 1999.

PALIERO, Carlo Enrico Paliero: "Criminalità economica e criminalità organizzata: due paradigmi a confronto". En: Barillaro, Michele (ed.): Criminalità organizzata e sfruttamento delle risorse territoriali, Giuffrè, Milano, 2004.

PALMA, Alessandra: "Il controverso istituto del concorso esterno nei reati associativi”. En: Studium iuris, 2006.

PASCALI, Michelangelo: "Le camorre tra esibizione di violenza e occultamento degli affari". En: Diritto e giustizia minorile, N. ${ }^{\circ} 1-2,2016$.

PASCALI, Michelangelo: "Malamusica". Neomelodia e legalità. Liguori, Nápoles, 2014.

PASCALI, Michelangelo: Camorra, economia e società. Ontologia dei sistemi criminali e delle ingerenze illecite nell'area dei pubblici appalti. Giappichelli, Turín, 2012. 
PASCALI, Michelangelo: Progetto Scampia. Sulla questione della periferia nord di Napoli. Giappichelli, Turín, 2017.

PENNISI, Angelo (ed.): La giustizia penale minorile. Formazione, devianza, diritto e processo. Giuffrè, Milán, 2012.

PÉREZ CEBADERA, María Ángeles: "La prueba del origen ilícito de los bienes y el decomiso ampliado". En: González-Cuéllar Serrano, Nicolás, Sanz Hermida, Ágata María, Ortiz Pradillo, Juan Carlos (eds.): Problemas actuales de la justicia penal. Colex, Madrid, 2013.

PÉREZ LUÑO, Antonio Enrique: La universalidad de los derechos humanos y el Estado constitucional. Universidad Externado de Colombia, Bogotá, 2002.

PISANI, Mario: "Criminalité organisée et coopération internacionale". En: Gutiérrez-Alviz Conradi, Faustino, Valcárcel López, Marta (eds.): La cooperación internacional frente a la criminalidad organizada. Universidad de Sevilla. Secretariado De Publicaciones, Sevilla, 2001.

POMANTI, Pietro: "Principio di tassatività e metamorfosi della fattispecie: l'art. 416 bis c.p.”. En: Archivio penale, 2017 en http://www. archiviopenale.it/File/DownloadArticolo? codice $=1 \mathrm{c} 733 \mathrm{dec}-05 \mathrm{c} 5-487 \mathrm{a}-$ b858-6497c213de53\&idarticolo $=15089$.

PONTI, Gianluigi: "Criminalità organizzata e criminologia". En: Bandini, Tullio, Lagazzi, Marco, Marugo, Maria Ida (eds.): La criminalità organizzata. Moderne metodologie di ricerca e nuove ipotesi esplicative. Giuffrè, Milano, 1993.

PRIETO, Evaristo: "Excepción y normalidad como categorías de lo político". En: Cancio Meliá, Manuel, Pozuelo Pérez, Laura (eds.): (eds.): Política criminal en vanguardia: Inmigración clandestina, terrorismo, criminalidad organizada. Civitas, Navarra, 2008.

PRIOLO, Giuseppe: "Legislación italiana de lucha contra las infiltraciones de la mafia en las Instituciones". En: Cámara de Landa, Enrique, Morabito, Stefano (eds.): Mafia, 'Ndrangheta, Camorra. En los entresijos del poder paralelo. Universidad de Valladolid, Valladolid, 2005.

RUIZ RODRÍGUEZ, Luís Ramón, GONZÁLEZ AGUDELO, Gloria: "El factor tecnológico en la expansión del crimen organizado". En: Puente Aba, Luz María, Zapico Barbeito, Mónica, Rodríguez Moro, Luis (eds.): 
Criminalidad organizada, e inmigración. Retos contemporáneos de la política criminal. Comares, Granada, 2008.

SALES, Isaia: La camorra le camorre. Editori riuniti, Roma, 1993.

SALES, Isaia: Storia dell'Italia mafiosa. Rubettino, Soveria Mannelli (Cz), 2015.

SALES, Isaia, "Minorenni estorsori della camorra, la «riserva dei boss»". En: https://www.ilmattino.it/napoli/cronaca/minorenni_estorsori_ camorra_commento_isaia_sales-4191648.html.

SÁNCHEZ GARCÍA DE PAZ, Isabel: "Problemas de legitimidad de una respuesta excepcional frente a las organizaciones criminales". En: Cancio Meliá, Manuel, Pozuelo Pérez, Laura (eds.): (eds.): Política criminal en vanguardia: Inmigración clandestina, terrorismo, criminalidad organizada. Civitas, Navarra, 2008.

SÁNCHEZ GARCÍA DE PAZ, Isabel: La criminalidad organizada: aspectos penales, procesales, administrativos y policiales. Dykinson, Madrid, 2005.

SANTINO, Umberto: La mafia interpretata. Dilemmi, stereotipi, paradigmi. Soveria Mannelli, Catanzaro, 1995.

SAUTTO, Dario: "Castellammare, falò dell'Immacolata con messaggio della camorra: «Pentiti bruciati»". En: https://ilmattino.it/napoli/ cronaca/castellammare_falo_immacolata_messaggio_camorra_pentiti_ bruciati-4159601.html.

SAVIANO, Roberto: "Il potere della camorra a stelle e strisce. I Casalesi alla conquista dell'America". En: la Repubblica, edición napolitana, de 29 de julio de 2011.

SAVONA, Erneso Ugo: "Le organizzazione criminali in Europa viste dall'esperienza italiana”. En: Fiandaca, Giovanni, Visconti, Costantino (eds.): Scenari di mafia. Orizzonte criminologico e innovazioni normative. Giappichelli, Turín, 2010.

SAVONA Ernesto, RICCARDI Michele (eds.): From illegal markets to legitimate businesses: the portfolio of organised crime in Europe. Final Report of Project OCP - Organised Crime Portfolio, Transcrime, Trento, 2015. 
SCIARRONE, Rocco (ed.): Mafie del Nord. Strategie criminali e contesti locali. Donzelli, Roma, 2014.

SINDONI, Angelo: "Mafia, Camorra, 'Ndrangheta: el immaginario colectivo y la evolucion". En: Cámara de Landa, Enrique, Morabito, Stefano (eds.): Mafia, 'Ndrangheta, Camorra. En los entresijos del poder paralelo. Universidad de Valladolid, Valladolid, 2005.

SMITH, Dwight C. Jr.: "Mafia: The Prototypical Alien Conspiracy". En: Annals of the American Academy of Political Science and Social Science, vol. 423, 1976.

SMITH, Dwight C. Jr.: "The Alien Conspiracy Theory: aka The Elephant in the Front Parlor". En: The European Review of Organised Crime, $\mathrm{N}^{\circ}$ 3(1), 2016.

SOLÍS DELGADILLO, Juan Mario, MORICONI BEZERRA, Marcelo: "La violencia letal en América Latina: un flagelo heterogéneo pero generalizado". En: Solís Delgadillo, Juan Mario, Moriconi Bezerra, Marcelo (eds.): Atlas de la Violencia en América Latina. Universidad Autónoma de San Luis Potosí, San Luis Potosí, 2018.

TOSCANO, Salvo: "Il procuratore nazionale antimafia: «Sì alla vendita dei beni confiscati»". En: http://livesicilia.it/2017/02/28/il-procuratorenazionale-antimafia-si-alla-vendita-dei-beni-confiscati_831385/.

TRIBUNALE DI ROMA: "Ordinanza sull'applicazione delle misure cautelari - procedimento penale $\mathrm{N}^{\circ} 30546 / 10$ R.G.N.R.", 28 de noviembre de 2014. En: https://www.giuliocavalli.net/wp-content/uploads/2014/12/ ORDINANZA-MONDO-DI-MEZZO.pdf.

TURONE, Giuliano: Il delitto di associazione mafiosa. Giuffré, Milán, 2008.

VAL Eusebio: "Vuelve Gomorra". En: https://www.lavanguardia. com/internacional/20150913/54435240477/vuelve-gomorra. html\#ixzz3lcQxEoq4.

VELÁZQUEZ GARCÍA, Sara: "Muertos que susurran, crímenes en la Italia fascista. El éxito de la mezcla de géneros en la serie El Comisario Ricciardi de Maurizio de Giovanni”. En: Sánchez Zapatero, Javier, Martín Escribà, Alex (eds.): La globalización del crimen. Literatura, cine y nuevos medios. Andavira Editora, Santiago de Compostela, 2017. 
VISCONTI, Costantino: "La mafia è dappertutto”: Falso!. Laterza, RomaBari, 2016.

VISCONTI, Costantino: "Strategie di contrasto dell'inquinamento criminale dell'economia: il nodo dei rapporti tra mafie e imprese". En: Rivista italiana di diritto e procedura penale, 2014.

WITKER, Iván: “De Lucky Luciano al 'chapo' Guzmán. Las redes criminales como actores malévolos de las relaciones internacionales". En: Sampó, Carolina, Troncoso, Valeska (eds.): El crimen organizado en América Latina: manifestaciones, facilitadores y reacciones. Instituto Universitario General Gutiérrez Mellado de Investigación sobre la Paz, la Seguridad y la Defensa, Madrid, 2017.

ZAFFARONI, Eugenio Raúl: "La creciente legislación penal y los discursos de emergencia". En: AA. VV.: Teorías actuales en el derecho penal. AdHoc, Buenos Aires, 1998.

ZAVALETA LOPEZ, Luis Alberto: "El efecto desestabilizador como fundamento de la política criminal contra la criminalidad organizada". En: https://legis.pe/efecto-desestabilizador-politica-criminal-criminalidadorganizada/

ZINITI, Alessandra: "E ora le donne di mafia allevano colletti bianchi. Come cambia la strategia dei clan". En: la Repubblica del 28 de enero de 2019.

ZUÑIGA RODRIGUEZ, Laura: "Criminalidad organizada, derecho penal y sociedad: apuntes para el análisis". En: Sanz Mulas, Nieves (ed.): $E l$ desafio de la criminalidad organizada. Comares, Granada, 2006

ZÚÑIGA RODRÍGUEZ, Laura: Criminalidad organizada y sistema de derecho penal. Contribución a la determinación del injusto penal de organización criminal. Comares, Granada, 2009.

ZÚÑIGA RODRÍGUEZ, Laura, BALLESTEROS SÁNCHEZ, Julio (eds.): La criminalidad organizada transnacional: una amenaza a la seguridad de los Estados democráticos. Ediciones Universidad de Salamanca, Valencia, 2017.

"1900 i grandi camorristi di New York: la Brooklyn Camorra". En: https:// pulcinella291.forumfree.it/?t=69888728. 
"Affari ad Aberdeen: la Scozia diventa l'Eldorado della camorra". En: https://www.ilmattino.it/napoli/cronaca/affari_ad_aberdeen_la_scozia_ diventa_39_eldorado_camorra-556274.html.

“Basso (Napoli)”. En: https://it.wikipedia.org/wiki/Basso_(Napoli).

“Camorra newyorkese”. En: https://it.wikipedia.org/wiki/Camorra newyorkese.

"Camorra, 1'allarme del procuratore Melillo: «Non solo bande, professionisti e imprese aiutano i clan»". En: https://www.ilmattino.it/napoli/cronaca/ camorra_allarme_procuratore_melillo-3286606.html.

"Decreto sicurezza: Libera, 'stop a vendita dei beni immobili confiscati ai privati'". En: https://www.agensir.it/quotidiano/2018/11/27/decretosicurezza-libera-stop-a-vendita-dei-beni-immobili-confiscati-aiprivati/?PageSpeed $=$ noscript.

"Fondo Rustico Amato Lamberti". En: https://it-it.facebook.com/FondoRustico-Amato-Lamberti-368044103267539/.

“Giuseppe Setola". En: https://it.wikipedia.org/wiki/Giuseppe_Setola.

"Gomorra, La serie". En: https://it.wikipedia.org/wiki/Gomorra_-_La_ serie.

"L'abrogazione articolo 41 bis". En: https://it.wikipedia.org/wiki/ Trattativa_tra_Stato_italiano_e_Cosa_nostra\#L'abrogazione_articolo_41_ bis.

"Le mani della politica su 58.000 miliardi di lire stanziati per la ricostruzione dopo il sisma dell'80". En: Il Tempo del 8 de abril de 2009.

"L'influence de Gomorra sur le Rap français!". En: https://www.youtube. $\mathrm{com} /$ watch? $=3 \mathrm{e} 3 \mathrm{WSg} 28 \mathrm{vsc}$.

"STOP a la mafia". En: https://www.larazon.es/internacional/stop-a-lamafia-PG13409006\#.Ttt1KrLLM2eudT8.

“The Camorra” En: The New York Times July 23 de julio de 1882.

"Torre Annunziata, l'ultimo gioco dei piccoli boss: le "finte stese". En: https://www.ilmattino.it/napoli/cronaca/torre_annunziata_1_ultimo_ gioco_dei_piccoli_boss_le_finte_stese-3473833.html. 


\section{VIDEOGRAFÍA}

CALABRIA Esmeralda, D'AMBROSIO Andrea, RUGGIERO Peppe: Biùtiful cauntri, 2007.

CAPUANO Antonio: Luna rossa, 2001.

CIOP \& KAF: Il segreto, 2013.

CUPELLINI Claudio: Una vita tranquilla, 2010.

DE ANGELIS Edoardo: Perez, 2014.

DI COSTANZO Leonardo: L'intervallo, 2012.

DI VAIO Gaetano: Largo Barracche, 2014.

FERRENTE Agostino, PIPERNO Giovanni: Le cose belle, 2013.

FRAZZI Andrea, FRAZZI Antonio: Certi bambini, 2004.

GAGLIARDI Giuseppe: Tatanka, 2011.

GARRONE Matteo: Gomorra, 2008.

MARRA Vincenzo: L'equilibrio, 2017.

MARRAZZO Joe: Dossier camorra, 1974 y 1981.

MARRAZZO Joe: Sciuscià '80, 1979.

MARRAZZO Joe: Terremoto sommerso, 1980.

MARRAZZO Joe: Terremoto anno quarto, 1984.

MONTESARCHIO Romano: Ritratti abusivi, 2013.

OLIVARES Diego: Veleno, 2017.

PATIERNO Francesco: Camorra, 2018.

RISI Marco: Fortapàsc, 2009.

SANTORO Michele: Robinù, 2016.

SCUTIERI Pasquale: I guappi, 1974.

TORNATORE Giuseppe: Il camorrista, 1986.

ZAMPA Luigi: Processo alla città, 1972. 